\title{
Optimization of Ultra wide Band Communication TCA and AVA by using PSO and IGWO-FU Algorithm
}

kalakuntla nishanth rao ( $\square$ kalakuntla.nishanth@gmail.com )

Dayananda Sagar University https://orcid.org/0000-0002-4968-7056

Vaibhav Meshram

Dayananda Sagar University

H. N. Suresh

Bangalore Institute of Technology

Research Article

Keywords: PSO, UTC, FSS, Antipodal Vivaldi Antenna, IGWO-FU

Posted Date: April 27th, 2021

DOI: https://doi.org/10.21203/rs.3.rs-413477/v1

License: (1) This work is licensed under a Creative Commons Attribution 4.0 International License.

Read Full License 


\title{
Optimization of Ultra wide Band Communication TCA and AVA by using PSO and IGWO-FU Algorithm
}

\author{
K. Nishanth Rao, Research Scholar, \\ Department of Electronics and Communication Engineering, \\ Dayananda Sagar University, Bangalore, Karnataka, India. \\ Vaibhav Meshram, Professor, \\ Department of Electronics and Communication Engineering, \\ Dayananda Sagar University, Bangalore, Karnataka, India. \\ H.N. Suresh, Professor, \\ Department of Electronics and Instrumentation Technology, \\ Bangalore Institute of Technology, Bangalore, India.
}

\begin{abstract}
:
Recently, with the faster pace of development on the sophisticated detection and stealth technology, an extensive attention is being paid to the reduction of Radar Cross Section (RCS) as it emerge in security and commercial application. Communication based applications have greater influence depends upon design architecture and performance of an antenna. This paper proposed FSS to triumph over varying values as considering design parameters. Here, Frequency Selective Surface (FSS) is optimized with a technique said to be Particle Swarm Optimization (PSO), used for tightly coupled array (PSO-UTC-FSS). This paper intends to design an Optimized Vivaldi antenna to enhance the gain performance. More particularly, optimization algorithms play a vital role in fine-tuning of parameter, and hence this paper intends to propose a new Improved Grey Wolf Optimization Algorithm with Fitness based Update evaluation (IGWO-FU), which is the enhanced version of traditional GWO. Using above concepts, losses are minimized and hence it improves radiation efficiency, gain measurement, bandwidth ratio etc. Finally, the performance of proposed IGWO-FU model is compared over other traditional algorithms with respect to gain, VSWR, directivity, charge and current distribution, return loss as well.
\end{abstract}

Key words: PSO, UTC, FSS, Antipodal Vivaldi Antenna, IGWO-FU .

\section{INTRODUCTION:}

Recently, FSS advance in antenna designing parameters play a major task in controlling interaction profile of the electromagnetic waves [1-2]. Owing to occurrence of resonance in FSS, reflection loss can be reduced. Usage of Tightly Coupled Arrays (TCAs) is most suitable choice for these applications provides wider bandwidth to achieve low profile and easier integration.

Of these, superstrate surface is the simplest approach used to perk up the performances of antenna includes bandwidth, broad side gain and directivity. But occurrence of any insignificant variations in superstrate surface affects the antenna performances [3-4]. Hence, dimension measurement must be carefully switched during designing processes. Combination of two calculating methods requires more time for replication and hard to extract results. Due to changes in frequency ranges for different applications, signal interference and radiation emission are very less compared to other methodologies. To overcome above disadvantages new technique called PSO-UTC-FSS is introduced to reduce interference and losses in bandwidth and frequency values [5].

In the recent era, the communication industry is grooming up massively with newer evolutionary techniques in wireless arena. The key component of wireless communication system is the antenna. An UWB antenna is a renowned type of antenna, which can fulfil the real-life applications demands like low power consumption, high data rates, simple hardware configuration [6-8]

Vivaldi antennas are one of the best choices for wide impedance bandwidth, planar configuration and low profile [9] [10]. A Vivaldi antenna generally comprises of end-fire radiation characteristics along with two variants, namely "coplanar and antipodal 
configuration". The AVA is highly utilized in stealth applications due to its radiation characteristics as well as attractive impedance [11]. A key factor to be considered for stealth application is its radar signature. Several techniques are reported in the literature to enhance the RCS performance of Vivaldi Antennas, which includes either semiconductor technology or PCT [12] [13]. Few other researchers have utilized the polarization converters, partial reflecting surfaces and artificial magnetic conductors in the design to improve the radar signature of the antenna. However, these antennas design techniques are limited in beam width and enlargement in overall antenna size; there is necessity to have an apt technique for AVA.

\section{PROBLEM STATEMENT:}

The major contribution of this research work is depicted below:

Design of resistive surfaces affected by various frequency selection factors are,

- Bandwidth $10 \mathrm{GHz}$

- Radiation Efficiency $75 \%$

- Gain 0.8 decibel

- Frequency $10 \mathrm{GHz}$

- Thickness $1 \mathrm{~mm}$

- The major intention of this research work is to design and Optimized Vivaldi antenna to enhance the gain performance.

- To achieve the optimized Vivaldi antenna design, the key parameters, which serves as the milestone of the antenna, viz. the Taper Length $\left(l_{t}\right)$, Aperture Width $\left(w_{a p}\right)$, Opening Rate, Slot Line Width $\left(w_{s}\right)$, Cavity Diameter $(d)$, Cavity to Taper Spacing $(s)$, Ground Plane Length $(l)$ and Ground Plane Width $(w)$, respectively are fine-tuned.

- As a novelty, the fine-tuning of the antenna parameters are achieved with a novel optimization algorithm referred as IGWO-FU, which is the conceptual improvement of GWO.

- Finally, the performance of proposed IGWO-FU model is compared over other traditional algorithms with respect to gain, VSWR, directivity, charge and current distribution, return loss as well.

\section{LITERATURE SURVEY}

\begin{tabular}{|l|l|l|l|}
\hline Author [Citation] & Methodology & Features \\
\hline $\begin{array}{l}\text { Shouyuan Shi et al } \\
{[14]}\end{array}$ & $\begin{array}{l}\text { Tightly coupled array } \\
\text { antenna with ultra } \\
\text { wide band technique } \\
\text { is used. }\end{array}$ & $\begin{array}{l}\text { Improves the } \\
\text { operational } \\
\text { bandwidth }\end{array}$ & $\begin{array}{l}\text { Gain reduced and } \\
\text { widens the beam } \\
\text { bandwidth due to the } \\
\text { variation in scan angle }\end{array}$ \\
\hline
\end{tabular}




\begin{tabular}{|c|c|c|c|}
\hline $\begin{array}{l}\text { Gabriele Minatti et } \\
\text { al [15] }\end{array}$ & $\begin{array}{l}\text { A Synthesis method } \\
\text { is used to control the } \\
\text { parameters of meta } \\
\text { surface antenna. }\end{array}$ & $\begin{array}{ll}- & \text { Improve } \\
\text { polarisation } \\
\text { - } \\
\text { Improved } \\
\text { phase } \\
\text { performance }\end{array}$ & $\begin{array}{l}\text { - For large bandwidth, } \\
\text { overall process rarely } \\
\text { requires a feedback }\end{array}$ \\
\hline L. Peng et al [16], & $\begin{array}{l}\text { The curved EZR- } \\
\text { MZR technique is } \\
\text { used to design } \\
\text { antenna. }\end{array}$ & $\begin{array}{ll}\text { - } & \text { Uniform } \\
\text { amplitude } \\
\text { - High design } \\
\text { efficiency }\end{array}$ & $\begin{array}{l}\text { To design circular } \\
\text { polarized antenna with } \\
\text { good features need } \\
\text { careful dimension and } \\
\text { position. }\end{array}$ \\
\hline $\begin{array}{l}\text { Yizhe Zhao et al } \\
\text { [17] }\end{array}$ & $\begin{array}{l}\text { A new antenna array } \\
\text { based on liquid } \\
\text { crystal technology is } \\
\text { used. }\end{array}$ & 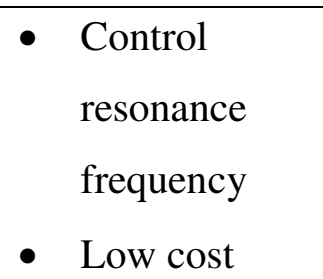 & $\begin{array}{l}\text { - Variation in } \\
\text { permittivity would } \\
\text { change the wavelength } \\
\text { guide. }\end{array}$ \\
\hline $\begin{array}{l}\text { Bichai Wang et al } \\
\text { [18] }\end{array}$ & $\begin{array}{l}\text { New spectrum and } \\
\text { energy efficient } \\
\text { technique is used. }\end{array}$ & $\begin{array}{ll}- & \text { High } \\
\text { efficiency } \\
\text { - } \\
\text { Low } \\
\text { complexity }\end{array}$ & $\begin{array}{l}\text { - RF chain used with } \\
\text { more number leads } \\
\text { energy consumption } \\
\text { and hardware cost is } \\
\text { high. }\end{array}$ \\
\hline $\begin{array}{l}\text { Muniyasamy et al. } \\
{[19]}\end{array}$ & $\begin{array}{l}\text { BALUN taper based } \\
\text { AVA }\end{array}$ & $\begin{array}{ll}\checkmark & \text { Reduction in } \\
& \text { size. } \\
\checkmark & \text { Extended } \\
& \text { bandwidth. }\end{array}$ & $\begin{array}{l}\text { Surface area of antenna } \\
\text { need to be reduced. }\end{array}$ \\
\hline $\begin{array}{l}\text { Chamaani et al. } \\
{[20]}\end{array}$ & $\begin{array}{l}\text { MOPSO based linear } \\
\text { array AVA }\end{array}$ & $\begin{array}{ll}\checkmark & \text { Low BW. } \\
\checkmark & \text { Low time- } \\
& \text { domain SLL. } \\
\checkmark & \text { Explores the } \\
\text { tradeoff } \\
\text { between the } \\
\text { BW and SLL }\end{array}$ & $\begin{array}{l}\text { Threshold level of } \\
\text { isolation is not } \\
\text { specified } \\
\text { correlated energy and } \\
\text { peak power patterns are } \\
\text { highly sensitive to noise }\end{array}$ \\
\hline $\begin{array}{l}\text { Chamaani et al. } \\
{[21]}\end{array}$ & MOPSO based AVA & $\begin{array}{r}\text { Provides } \\
\text { optimum } \\
\text { trade-off }\end{array}$ & $\begin{array}{l}\text { High fabrication cost } \\
\text { high complexity }\end{array}$ \\
\hline
\end{tabular}




\begin{tabular}{|c|c|c|c|}
\hline & & $\begin{array}{l}\text { between } \\
\text { solutions in a } \\
\text { 3D Pareto } \\
\text { front. } \\
\checkmark \text { Good } \\
\text { impedance } \\
\text { matching }\end{array}$ & \\
\hline $\begin{array}{l}\text { Boujemaa et al. } \\
\text { [22] }\end{array}$ & $\begin{array}{l}\text { Metamaterials based } \\
\text { AVA }\end{array}$ & $\begin{array}{ll}\checkmark & \text { Higher } \\
& \text { radiation } \\
& \text { performances } \\
\checkmark & \text { Improves } \\
& \text { antenna } \\
& \text { directivity }\end{array}$ & $\begin{array}{l}\text { Low BW } \\
\text { High bandwidth } \\
\text { limiting transition }\end{array}$ \\
\hline Dardeer et al. [23] & $\begin{array}{lr}\text { Elliptical } & \text { curve } \\
\text { shaped AVA with } \\
\text { NIM }\end{array}$ & $\begin{array}{ll}\checkmark & \text { Achieved } \\
\text { high input } \\
\text { impedance } \\
\text { bandwidth } \\
\checkmark & \text { Increase in } \\
\text { antenna array } \\
\text { gain }\end{array}$ & $\begin{array}{l}\text { Requires directional } \\
\text { UWB antenna }\end{array}$ \\
\hline Nath et al. [24] & $\begin{array}{l}\text { High Gain Vivaldi } \\
\text { antenna }\end{array}$ & $\begin{array}{l}\checkmark \text { In bore sight, } \\
\text { the low } \\
\text { frequency } \\
\text { gain is } \\
\text { increased }\end{array}$ & High cross polarization \\
\hline $\begin{array}{lll}\text { Dvorsky et } a l . \\
{[25]}\end{array}$ & $\begin{array}{l}\text { Portable miniaturized } \\
\text { AVA }\end{array}$ & $\begin{array}{ll}\checkmark & \text { Fractional } \\
& \text { bandwidth } \\
\checkmark & \text { Stable } \\
& \text { radiation } \\
& \text { patterns }\end{array}$ & $\begin{array}{l}\text { Low peak gain } \\
\text { High Cost }\end{array}$ \\
\hline Kumar et al. [26] & $\begin{array}{l}\text { Leaf Shaped } \\
\text { AVA based on GA }\end{array}$ & $\begin{array}{ll}\checkmark & \text { Low cross- } \\
\text { polarization } \\
\text { level }\end{array}$ & Low gain factor \\
\hline
\end{tabular}




\begin{tabular}{|l|l|l|l|}
\hline & $\checkmark$ & Reduction in \\
volumetric & size & \\
\hline
\end{tabular}

\section{METHODOLOGY}

\subsection{PSO-UTC-FSS:}

PSO methodology requires only solitary stage manoeuvre for iteration. It does not need progression of exchange from dual to authentic values of parameters involved in optimization procedure. PSO algorithm maintains intangible ease of non-specific algorithm while being much easier to execute and relate to design exertions with both distinct and constant design parameters. Parallel calculations have great collision on PSO in deceiving an amount of time required to improve performance.

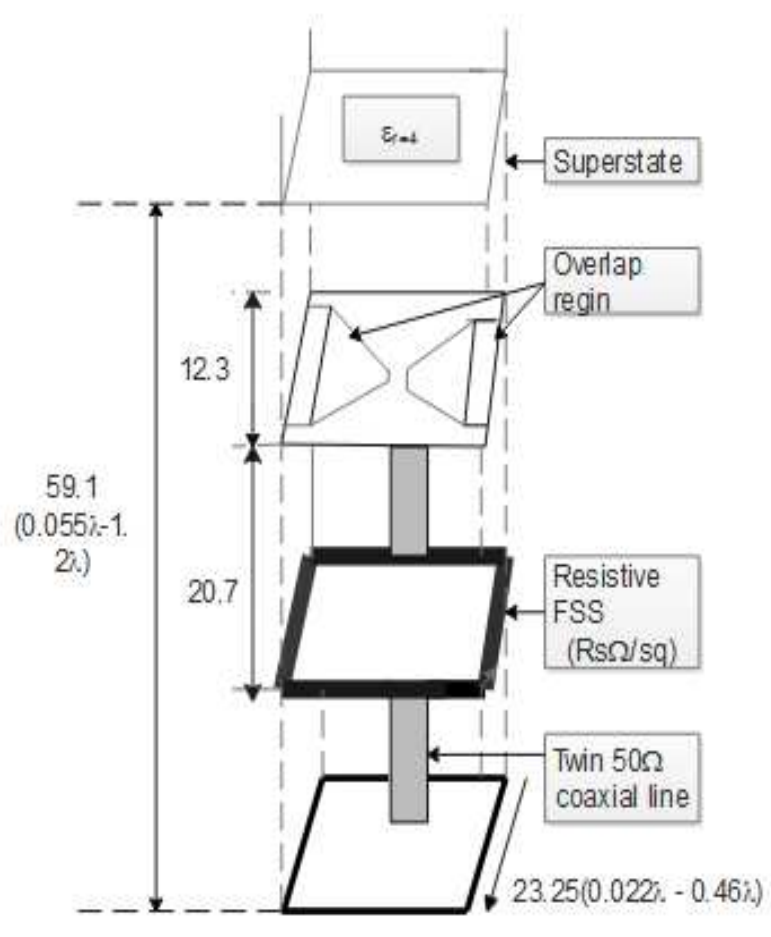

Fig.1: Individual cell of resistive FSS with tightly coupled Bowtie array

Above fig. 1revealed figure represents a tightly coupled bowtie array with a resistive FSS and a corresponding superstrate is introduced with them [27]. An efficient low profile [28] ultra wideband firmly coupled array utilizing FSS along with superstrate contains intrusion of the ground plane and array's bandwidth [29]. Victims in an array element can be minimized by suitable designing of superstrate [30]. It achieves low profile index about $0.055 \lambda$ with a bandwidth ratio of $21: 1$ and the proficient radiation of about $73 \%$ athwart band. 
Presence of ground plane limits the bandwidth of array whose terminals are coupled together by a capacitance [31]. Appropriate concern must take while a resistive element is utilized. The fig. 2 shows the overlapping of superstrate [32], FSS and optimal efficiency reduces the thickness to $\lambda / 4$ times than the existing one. Corresponding increase of the resistance value probably minimizes the width ratio at an appropriate range [33].

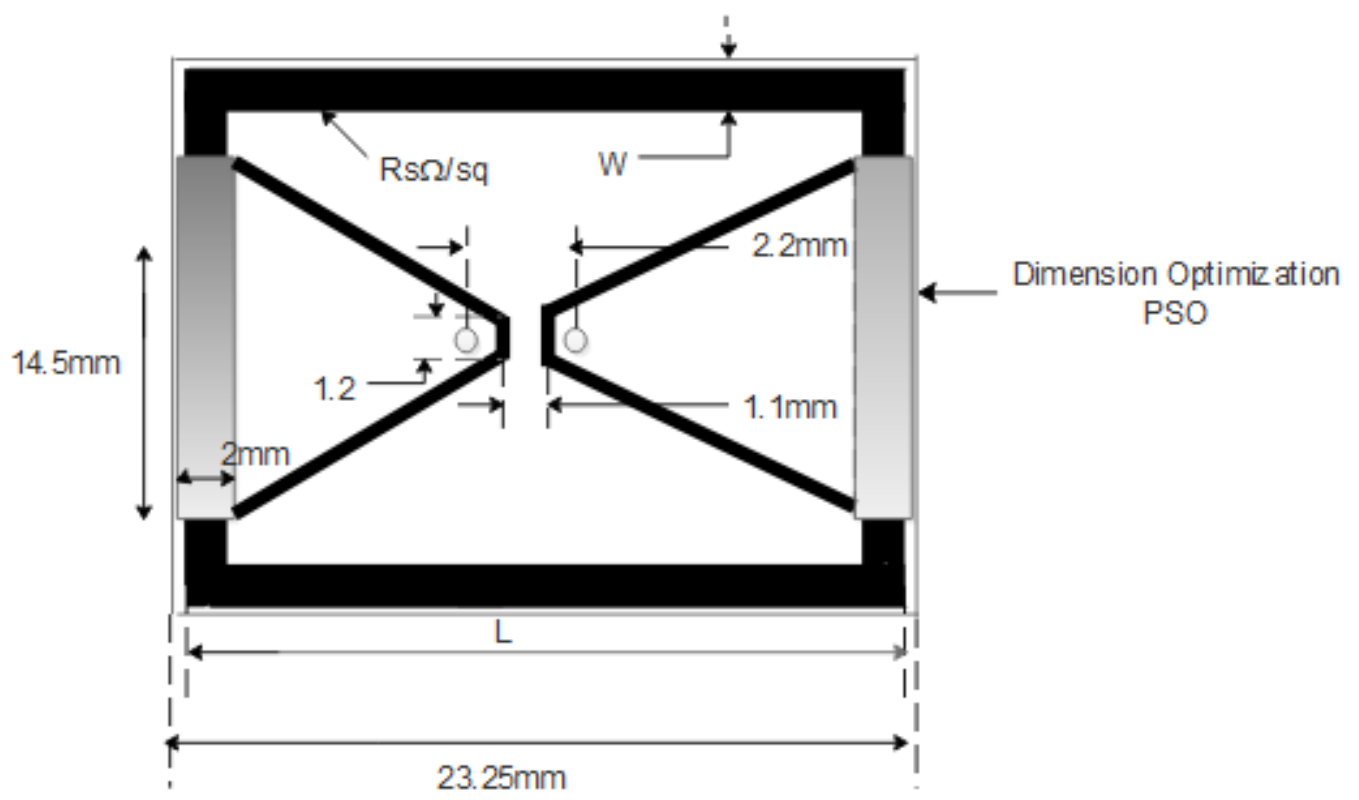

Fig.2: Top view of unit cell

\begin{tabular}{|l|l|}
\hline \multicolumn{2}{|l|}{ Algorithm 1: Proposed PSO Algorithm } \\
\hline Initialise the PSO Parameter \\
\hline \multicolumn{2}{|l|}{ The parameters Generate swarm } \\
\hline & Evaluate the fitness of particles \\
\hline & Record best fitness particles $\mathrm{Vn}, \mathrm{Xn}, \mathrm{w}, \mathrm{p}, \mathrm{c}$ and g \\
\hline & Record best fitness particles Xn \\
\hline & Evaluate the global best particles \\
\hline & Analyse the swarm meets the criteria \\
\hline & If yes \\
\hline & End \\
\hline & If else \\
\hline & Update velocity particle \\
\hline & Update position particle \\
\hline Update the global particles \\
\hline Return swarm criteria \\
\hline
\end{tabular}




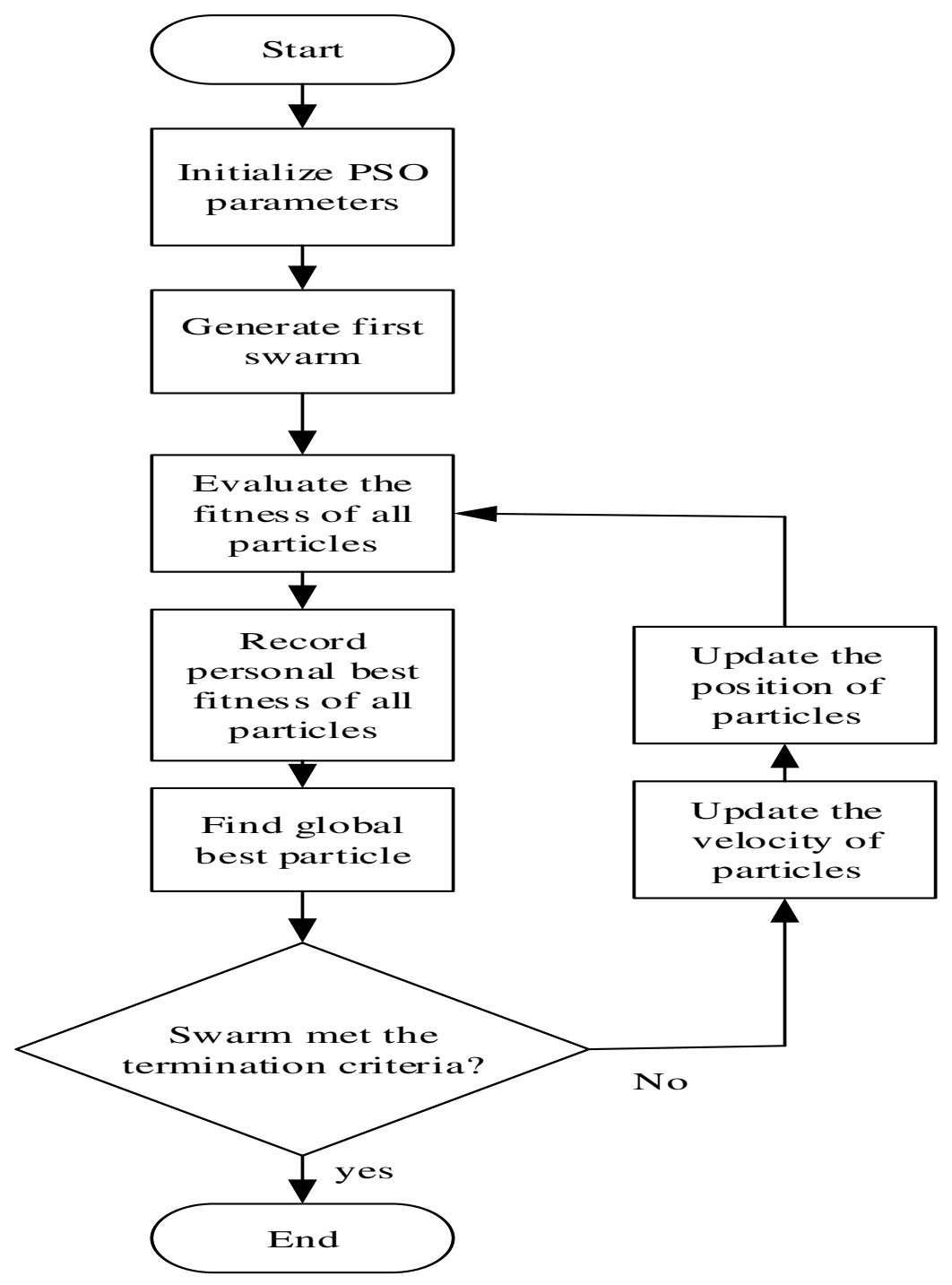

Fig.3: Flowchart of proposed PSO algorithm

\subsection{Proposed Algorithm for Optimal Parameter Tuning}

\section{A. Objective Function}

As said before, the selected antenna parameters are optimally tuned by a new IGWO-FU algorithm, and the input fed to the proposed algorithm is illustrated in Fig .The foremost objective of this research work is to maximize the antenna gain ( $G a$ ) of compact AVA with optimized parameters. The mathematical expression of the defined objective function $(O b j)$ is given in Eq. (1).

$$
\operatorname{Obj}=\operatorname{Max}(G a)
$$

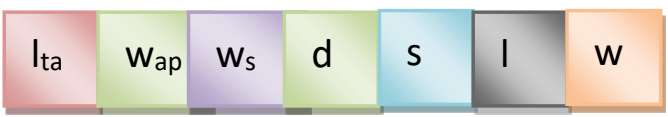

Fig 4. Solution Encoding

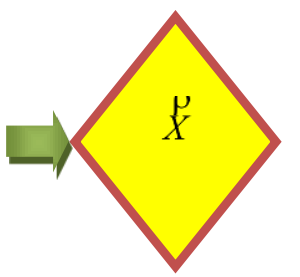




\section{B. Proposed IGWO-FU Algorithm}

Step 1: On the basis of the fitness (Fit), the position of the search agents is sorted. For illustration, if the count of search agents $=10(i=1,2,3, \ldots, 10)$ and if the highest fitness position $\left(X i_{\alpha}\right)$ is recorded by $5^{\text {th }}$ search agent, and the lowest fitness position $\left(X i_{\delta}\right)$ is recorded by $2^{\text {nd }}$ search agent. The other search agents occupy the position between the highest and the lowest fitness. Fig. 3 shows the sorted solution on the basis of fitness.
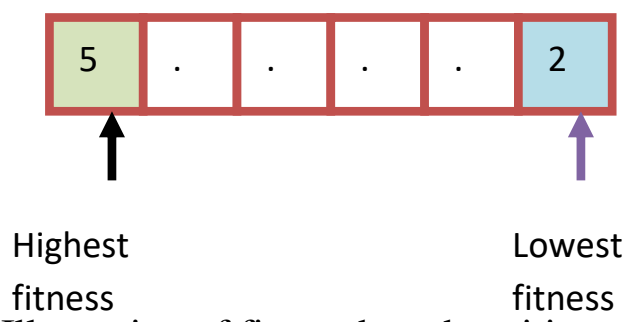

Fig 5. Illustration of fitness based position update

Step 2: Subsequently, the solution (exist in $1^{\text {st }}$ position of sorted list, i.e, $\dot{X}_{\alpha}$ ) is updated by using the mathematical formula expressed.

Step 3: The worst solution (last position in sorted list i.e, $\mathrm{Xi}_{\delta}$ ) is updated randomly by choosing an arbitrary number $\left(R a_{2}\right)$ in between the upper $(U B)$ and the lower bound $(L B)$ of the solutions.

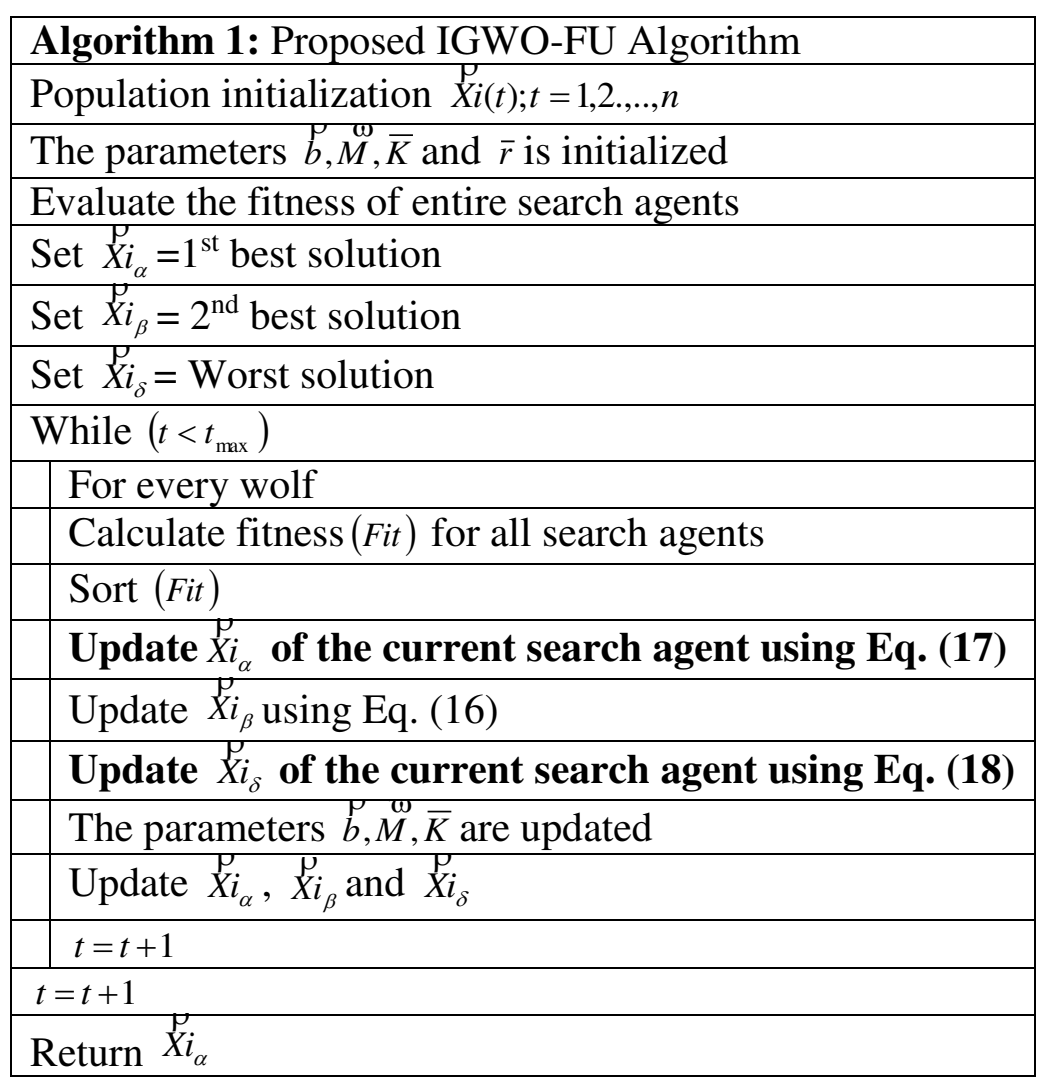




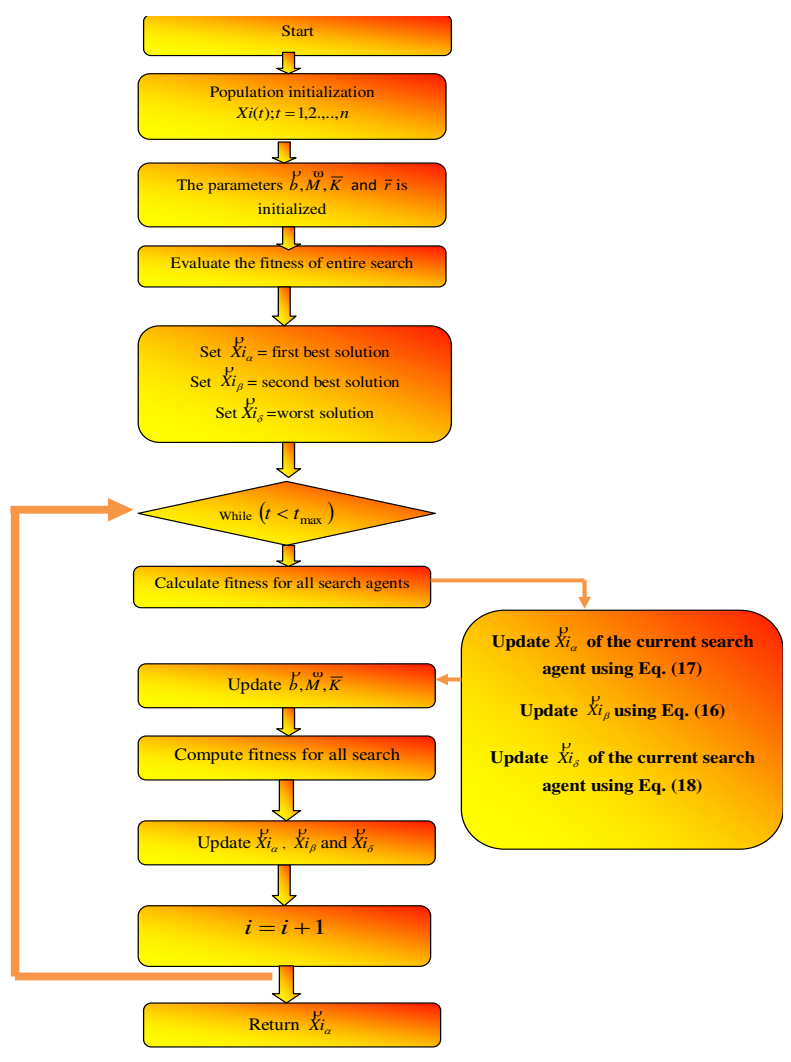

Fig 6. Flow chart of the proposed IGWO-FU model

\section{RESULT AND DISCUSSION}

Below diagrams represents proposed antenna design model. Simulation output provides frequency in GHZ.

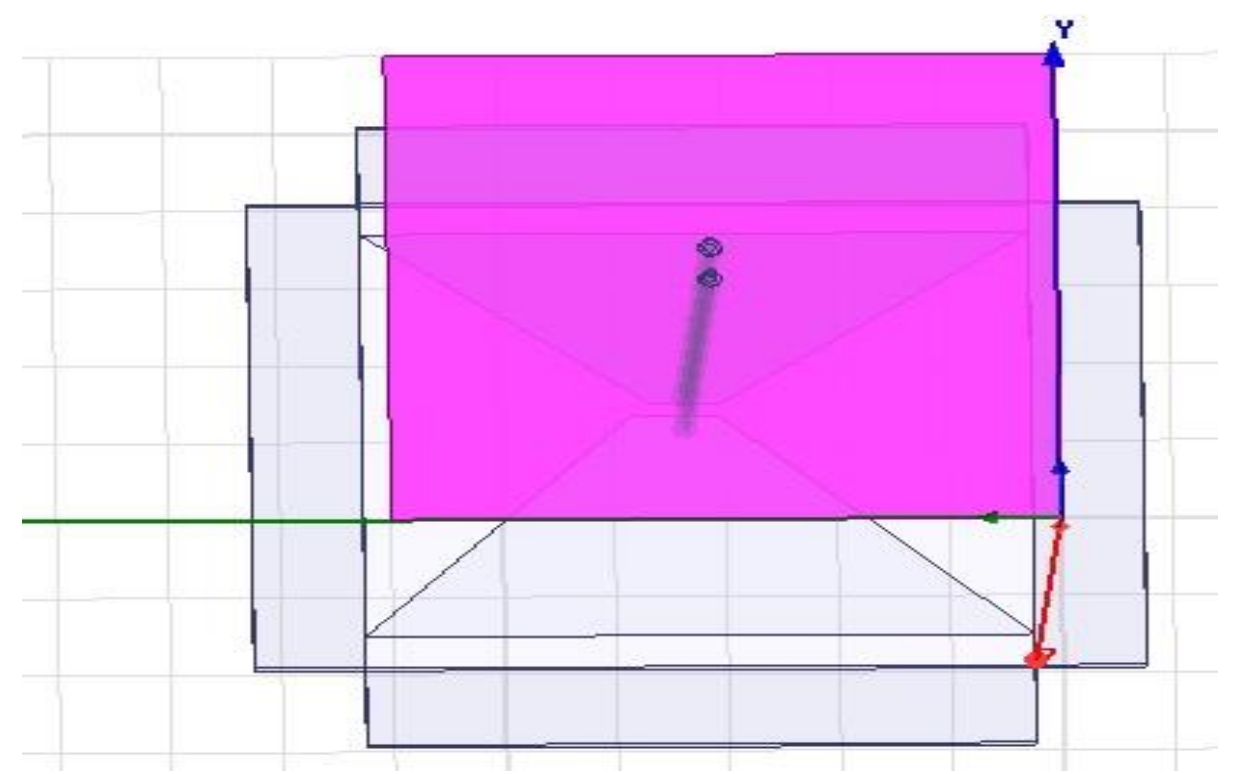

Fig.7 : Proposed HFSS model for bowtie antenna 
Graph fig 5 and 6, below shows S-parameter plot beside frequency. Ultra wideband antenna works at a large frequency range of 0 to $10 \mathrm{GHz}$. Bandwidth of antenna was about 10GHz. S-parameter value of antenna ranges from-580 decibel to 560 decibel. Method behind HFSS is the Software Limited Component Analysis. The Fig $7 \& 8$ shows the Radiation emission and radiation pattern of the respective antenna. The output results of the following figures indicate that the obtained frequency bandwidth, radiation losses of the antenna.

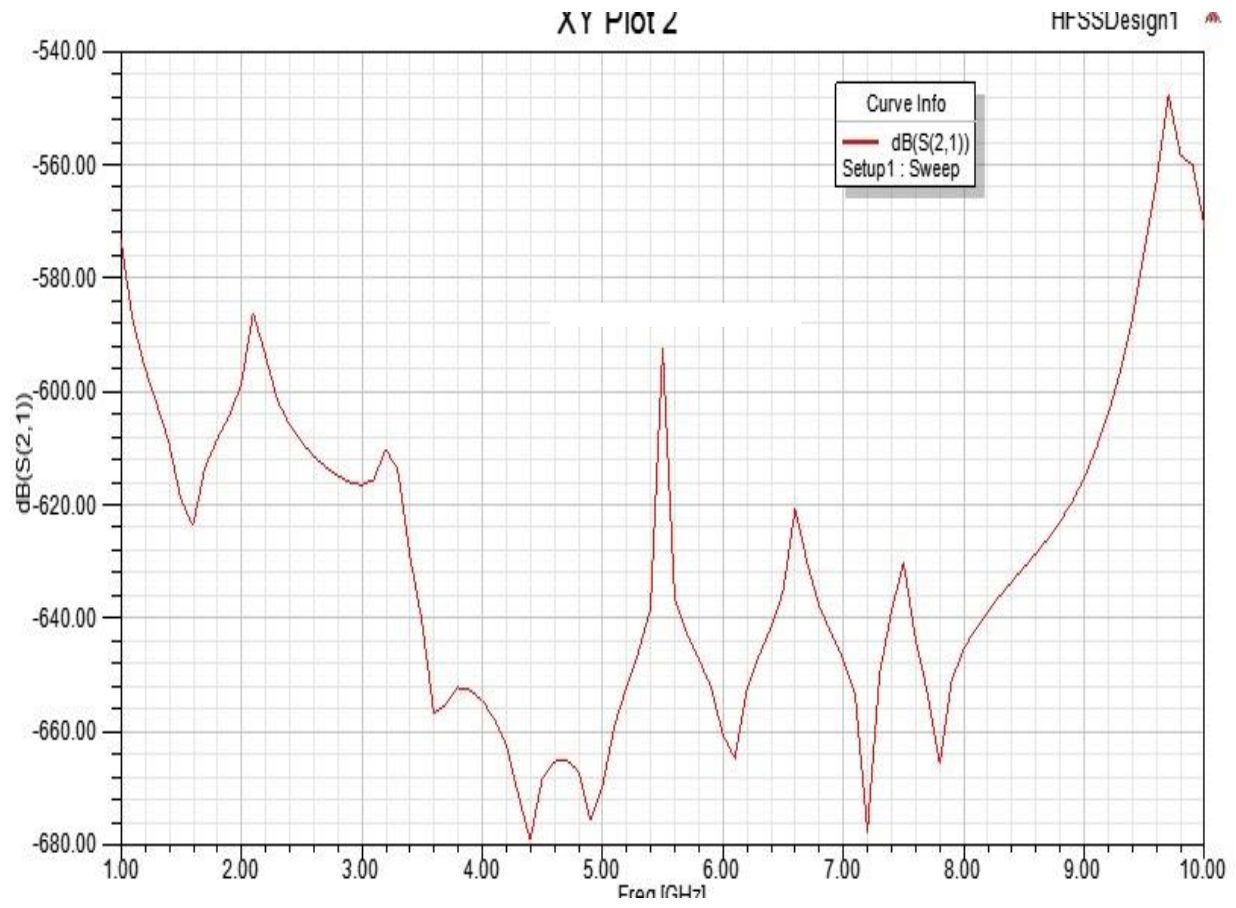

Fig.8: Output graph of the proposed model

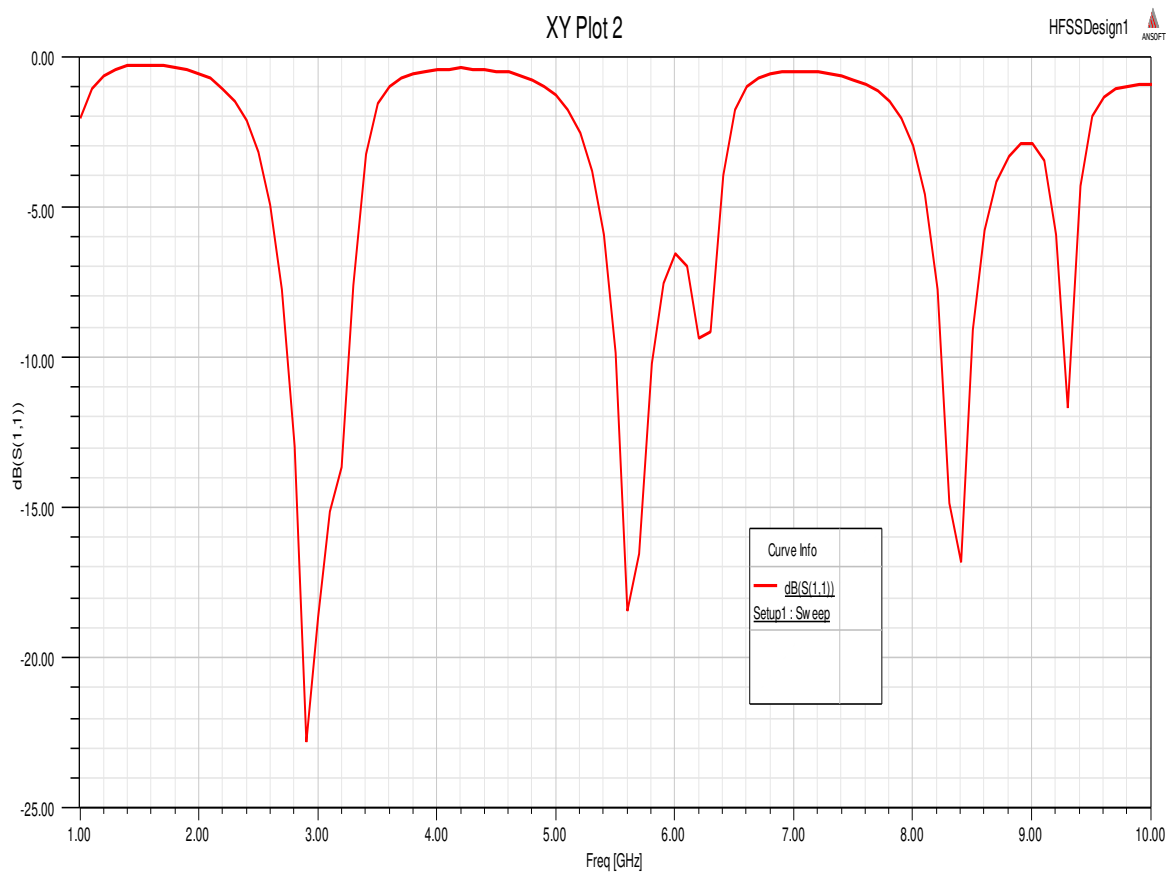

Fig.9: Output graph for Rectangular plot 

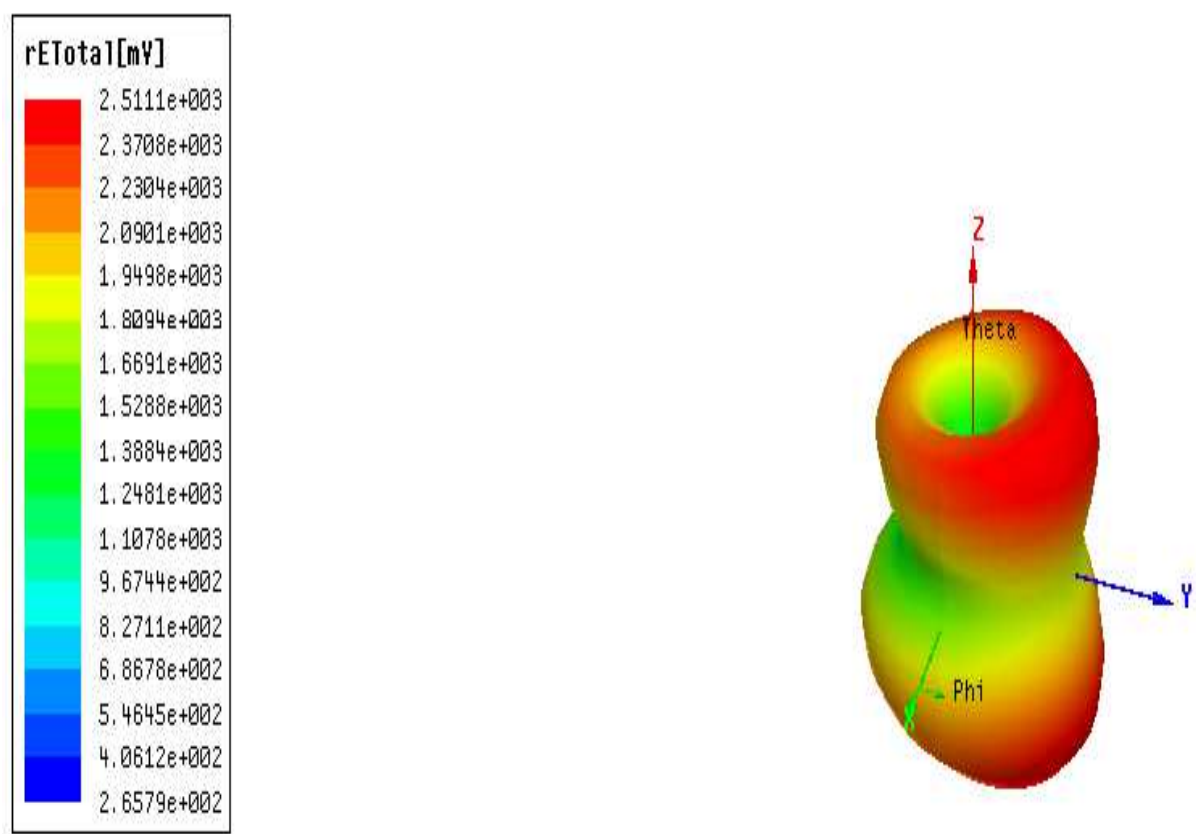

Fig.10: Output graph for polar plot of Radiation Emission

\section{A. Antenna Design}

The optimized proposed AVA model evolved from the reference antenna after undergoing various modifications. The geometry of the reference antenna (Simple Vivaldi antenna) is illustrated in Fig. 11 .

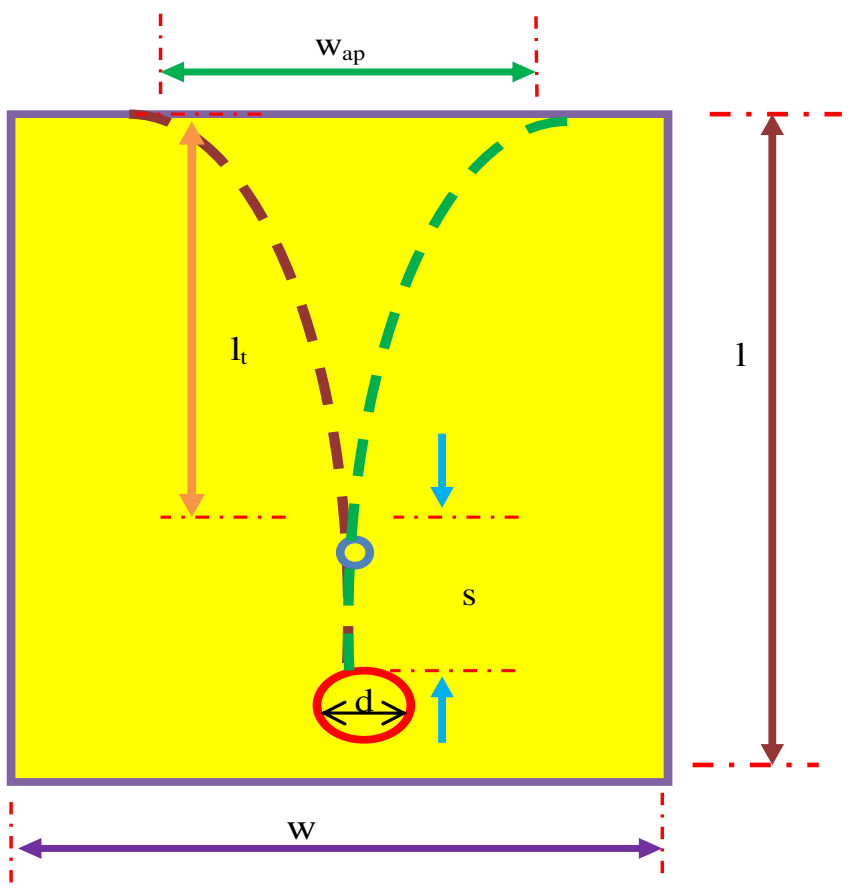

Fig 11. Illustration of geometry of Simple vivaldi antenna

The proposed optimization assisted antipodal Vivaldi antenna for UWB communication using was implemented in MATLAB and the results acquired are noted. The proposed 
IGWO-FU model is evaluated over the traditional models like ABC [34], DE [35], ABC-DE and PSO [36] in terms of gain, Return loss and VSWR by varying the frequency of the tilt angle.

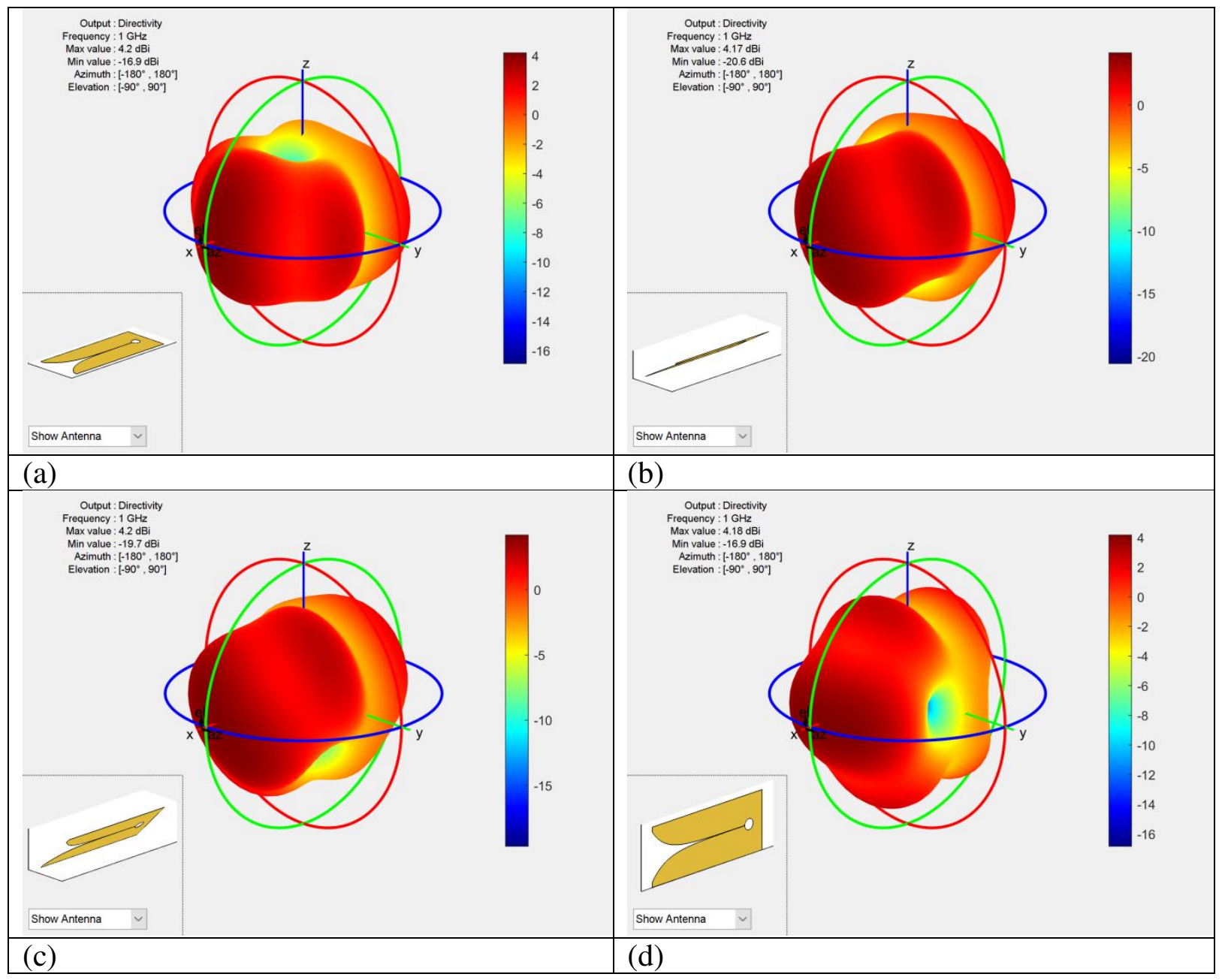

Fig 12: 3D pattern of Vivaldi antenna at the rotating angle of (a) $0^{\circ}$ (b) $30^{\circ}$ (c) $45^{\circ}$ (d) $90^{\circ}$

"Directivity $(D)$ is the quantitative measure of an antenna's ability to concentrate radiated power per unit solid angle in a certain direction and it is highly dependent on the threedimensional pattern of an antenna". The directivity of antenna is expressed mathematically in Eq.in which $R_{\text {sspecific }}$ and $R_{\text {reference }}$ is the radiation intensity of the given antenna and the radiation intensity of the reference antenna, respectively.

$D=\frac{R_{\text {specific }}}{R_{\text {reference }}}$ 


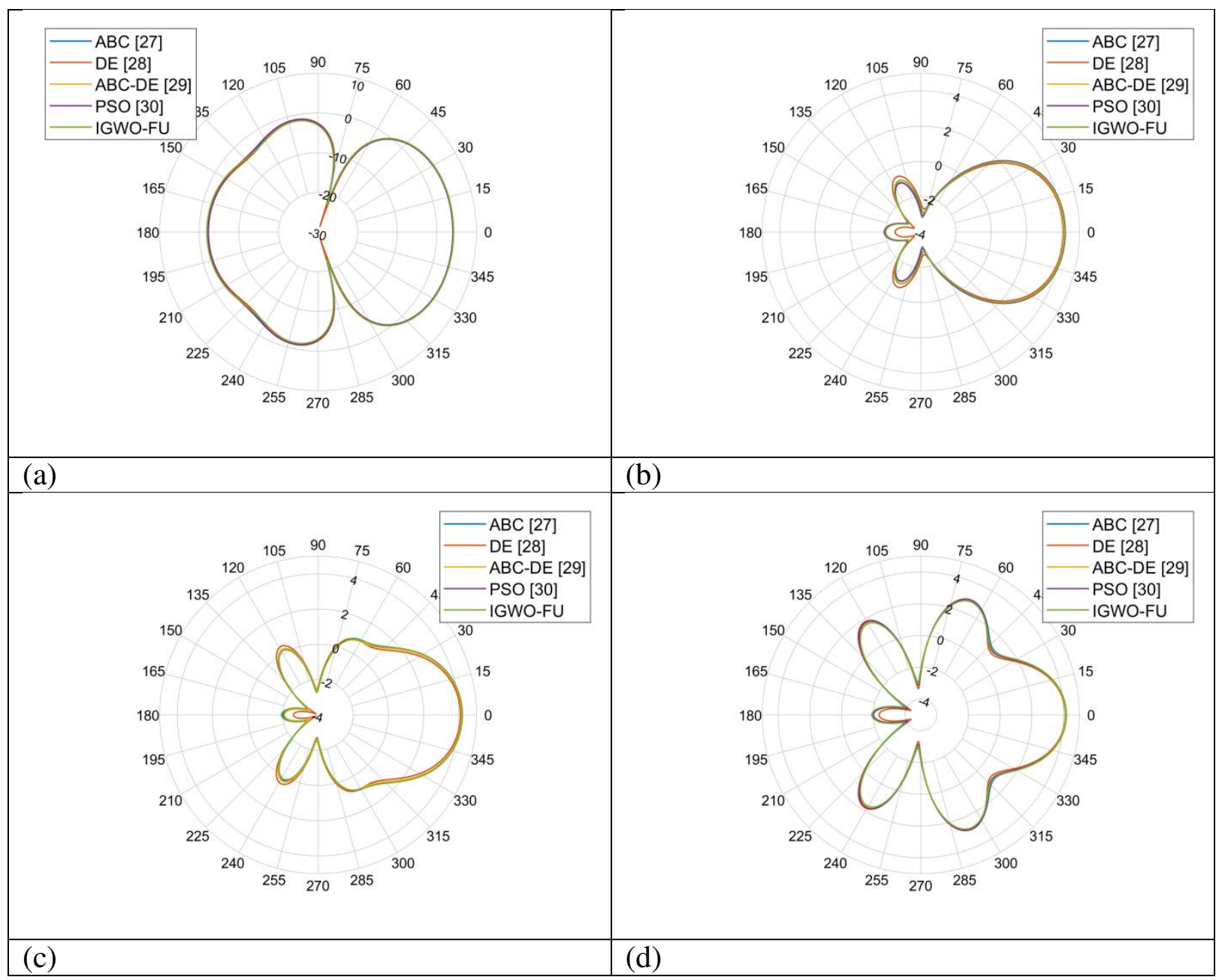

Fig 13. Polar plot exhibiting the directivity of optimized antenna for traditional and proposed IGWO-FU at (a) tilt angle $=0^{\circ}$ (b) tilt angle $=30^{\circ}$, (c) tilt angle $=45^{\circ}$ and (d) tilt angle $=90^{\circ}$.

Table I: Optimal Values of the S-Parameter of mofified AVA with IGWO-FU

\begin{tabular}{|l|l|}
\hline Algorithm & S-parameter \\
\hline ABC[27] & $0.72637-0.31242 \mathrm{i}$ \\
\hline $\mathrm{DE}[28]$ & $0.71902-0.29712 \mathrm{i}$ \\
\hline ABC-DE[29] & $0.71413-0.34004 \mathrm{i}$ \\
\hline PSO[30] & $0.71562-0.31998 \mathrm{i}$ \\
\hline IGWO-FU & $0.71844-0.32769 \mathrm{i}$ \\
\hline
\end{tabular}

\section{CONCLUSION:}

Proposed methodology eliminates an interference of array's bandwidth and ground plane. This paper presents combined evaluation of Frequency Selection Surface (FSS) along with 
PSO which has several advantages like increased reliability, efficiency and ease of implementation.

The current research has achieved the objective of designing an Optimized Vivaldi antenna to enhance the gain performance. The optimized Vivaldi antenna was designed by fine- tuning the antenna parameters like taper length $l_{t}$, aperture width $w_{a p}$, Slot Line width $w_{s}$, cavity diameter $d$, Cavity to taper spacing $s$, Ground Plane length $l$ and ground plane width $w$, respectively. As a major contribution, these antennas were tuned in an optimal way by introducing IGWO-FU, which was the enhanced version of traditional GWO. Finally, the performance of proposed IGWO-FU model was compared over other traditional algorithms with respect to gain, VSWR, directivity, charge and current distribution, return loss as well. Moreover, at the frequency value $=7 e^{9}$, the IGWO-FU is $52 \%, 8 \%, 40 \%$ and $4 \%$ superior to the traditional models like ABC, DE, ABC-DE and PSO, respectively at tilt angle of $45 \%$ in terms of VSWR. at tilt angle of $0^{\circ}$, The IGWO-FU in terms of gain is $30 \%, 5.2 \%, 7.3 \%$ and $15.7 \%$ better than the traditional models like DE, ABC-DE, ABC and PSO, respectively at frequency $=7 e^{9}$. Thus, from the evaluation, it is obvious that the proposed IGWO-FU model has achieved the improved gain performance of the optimized AVA.

\section{DECLARATION}

I K Nishanth Rao, declare that the Submitted Research Paper is my original work and no part of it has been published anywhere else in the past. I take full responsibility, that if in future, the paper is found invalid according to basic rules, the last decision will be of the Authorities concerned. Any form of plagiarism will lead to disqualification of the paper.

\section{REFERENCES:}

[1] Singh, Surya Prakash, Abhishek Kumar Jha, and M. Jaleel Akhtar. "Design of broadband superstrate FSS for terahertz imaging and testing applications", Microwave and RF Conference (IMaRC), MTT-S International IEEE, 2016.

[2] Sakakibara, Kunio, et al. "Reflection-loss reduction of dielectric plate by reflection-phase control of Frequency Selective Surface." Electromagnetic: Applications and Student Innovation Competition (iWEM), 2017 International Workshop on IEEE, 2017.

[3] Farhat, Iman O., et al. "Genetic algorithm application on a tightly coupled array antenna" Antennas and Propagation (EUCAP), 2017 11th European Conference on IEEE 2017.

[4] Yadav, Sanjeev, "A novel band rejects frequency selective surfaces for Bluetooth, Wi-MAX and WLAN applications." India Conference (INDICON), 2016 IEEE Annual IEEE, 2016.

[5] William F. Moulder, "Superstrate-Enhanced Ultra wideband Tightly Coupled Array with Resistive FSS" IEEE Transactions on Antennas and Propagation vol.60, no: 9, 2016.

[6]F. Yuan, G. Wang, H. Xu, T. Cai, X. Zou and Z. Pang, "Broadband RCS Reduction Based on Spiral-Coded Metasurface," IEEE Antennas and Wireless Propagation Letters, vol. 16, pp. 3188-3191, 2017.

[7] C. Deng and Y. Xie, "Design of Resistive Loading Vivaldi Antenna," IEEE Antennas and Wireless Propagation Letters, vol. 8, pp. 240-243, 2009.

[8] Tayyab A. Khan, Jianxing Li, Zhiyuan Li, Muhammad Abdullah, Anxue Zhang,"Design of a Vivaldi antenna with wideband reduced radar cross section",AEU - International Journal of Electronics and Communications,vol.95, pp.47-51,October 2018.

[9] Furat Abayaje, Pascal Febvre,"A customized reduced size Antipodal Vivaldi Antenna used in Wireless Baseband Transmission for short-range communication",AEU - International Journal of Electronics and Communications, vol.70,no.12,pp.1684-1691,December 2016.

[10] A. Z. Hood, T. Karacolak and E. Topsakal, "A Small Antipodal Vivaldi Antenna for Ultrawide-Band Applications," IEEE Antennas and Wireless Propagation Letters, vol. 7, pp. 656-660, 2008. 
[11] M. Moosazadeh and S. Kharkovsky, "A Compact High-Gain and Front-to-Back Ratio Elliptically Tapered Antipodal Vivaldi Antenna With Trapezoid-Shaped Dielectric Lens," IEEE Antennas and Wireless Propagation Letters, vol. 15, pp. 552-555, 2016.

[12] Y. Wang, G. Wang and B. Zong, "Directivity Improvement of Vivaldi Antenna Using Double-Slot Structure," IEEE Antennas and Wireless Propagation Letters, vol. 12, pp. 1380-1383, 2013.

[13] Y. Liu, W. Zhou, S. Yang, W. Li, P. Li and S. Yang, "A Novel Miniaturized Vivaldi Antenna Using Tapered Slot Edge With Resonant Cavity Structure for Ultrawideband Applications," IEEE Antennas and Wireless Propagation Letters, vol. 15, pp. 1881-1884, 2016.

[14] Shi, Shouyuan, "Ultra wideband optically fed tightly coupled phased array." Journal of Light wave Technology IEEE Journals \& Magazines, Volume: 33, Pages: 4781 - 4790, Issue: 23 , Papers (9), 2015.

[15] Gabriele Minatti, Francesco Caminita, "Synthesis of modulated-meta surface antennas with amplitude, phase and polarization control", IEEE Journals \& Magazines, Page(s): 3907 - 3919, Volume: 64, Issue: 9 , Pages: 3907 - 3919, Papers (48), 2016.

[16] Lin Peng ; Kai Sun, "EZR-MZR Resonators for Compact Low-profile Omni-directional Circular-polarized Antenna Design", Article Sequence Number: 4600615, Papers (2), Volume: 9 , Issue: 4,IEEE Journals \& Magazines, 2017.

[17] Yizhe Zhao, Cheng Huang, "A Frequency and Pattern Reconfigurable Antenna Array Based on Liquid Crystal Technology", Article Sequence Number: 4600307, Volume: 9, Issue: 3, Papers (11), IEEE Journals \& Magazines, 2017.

[18] Bichai Wang, Ling long Dai, " Spectrum and Energy-Efficient Beam space MIMO-NOMA for Millimetre-Wave Communications Using Lens Antenna Array", IEEE Journals \& Magazines, Volume: 35 , Issue: 10, Pages: 2370 - 2382, Papers (50), 2017.

[19] Amutha Muniyasamy, Karthipan Rajakani,"UWB radar cross section reduction in a compact antipodal Vivaldi antenna",AEU - International Journal of Electronics and Communications, vol.99, pp.369-375,February 2019.

[20] S. Chamaani, M. S. Abrishamian and S. A. Mirtaheri, "Time-Domain Design of UWB Vivaldi Antenna Array Using Multiobjective Particle Swarm Optimization," IEEE Antennas and Wireless Propagation Letters, vol. 9, pp. 666-669, 2010.

[21] S. Chamaani, S. A. Mirtaheri and M. S. Abrishamian, "Improvement of Time and Frequency Domain Performance of Antipodal Vivaldi Antenna Using Multi-Objective Particle Swarm Optimization," IEEE Transactions on Antennas and Propagation, vol. 59, no. 5, pp. 1738-1742, May 2011.

[22] Mohamed-Ali Boujemaa,Rabiaa Herzi,Fethi Choubani,Ali Gharsallah,"UWB Antipodal Vivaldi antenna with higher radiation performances using metamaterials",Applied Physics A,October 2018.

[23] Osama M. Dardeer, Tamer G. Abouelnaga, Ashraf S. Mohra, Hadia M. El-Hennawy,"A Novel UWB Vivaldi Antenna Array for Radar Applications",International Journal of Scientific \& Engineering Research, vol.7, no.5, May-2016

[24] G. Veerendra Nath, L.S. Lakshmi Sowjanya,"A BALANCED ANTIPODAL VIVALDI ANTENNAn WITH IMPROVED RADIATION CHARACTERISTICS", International Journal of Emerging Trends in Engineering and Development, vol.5, no.6, September 2016.

[25] Dvorsky, Harihara S. Ganesh,and S. Sadhish Prabhu,"Design and Validation of an Antipodal Vivaldi Antenna with Additional Slots",2019.

[26] R. Kumar, B. R. Behera and P. Suraj, "A Modified Leaf Shaped Antipodal Vivaldi Antenna for UWB Applications," 2018 IEEE Indian Conference on Antennas and Propogation (InCAP), Hyderabad, India, pp. 14,2018.

[27] Riad Yahiaoui, "Highly directive emission from a Frequency Selective Surface based Fabry-Pérot cavity antenna," International Congress on Telecommunication and Application, 2012.

[28] Simone Genovesi, "Particle Swarm Optimization for the Design of Frequency Selective Surfaces" IEEE Antennas and Wireless Propagation letters 2016.

[29] Yimin D.Zhang, "DOA Estimation Exploiting Coprime Arrays with Sparse Sensor Spacing" Naval Research centre for Advanced Communication 2014.

[30] J. Kasemodel, C.C Chen and J.L. Volakis," Wideband Conformal Array with Integrated supply and Corresponding Network for Wide-Angle Scanning," IEEE Trans. Antennas \& Propagat., Vol. 61 (9), pp. 4528 4537, Sept. 2013

[31] J.P. Doane, K. Sertel \& J.L.Volakis, A Wideband, Wide Scanning Firmly Coupled Dipole Array with Integrated Balun (TCDA-IB)," IEEE Trans. Antenna Propagat., Vol. 61 (9), pp. 4538 - 4548, Sept. 2013

[32] Ali A. Al-Azza, Ammar A. Al-Jodah, "Spider Monkey Optimization: A Novel Technique for Antenna Optimization”, Volume: 15, Page(s): 1016 - 1019Papers (10), IEEE Journals \& Magazines, 2016. 
[33] B. A. Munk, "Broadband Wire Arrays in Fixed Antenna Arrays and FSS", Ed: John Wiley \& Sons, Inc., Hoboken, NJ, USA, 2003, pp. 181-213.

[34] D.KarabogaB.Basturk, " On the performance of artificial bee colony (ABC) algorithm", Applied Soft Computing, vol. 8, no. 1, pp. 687-697, 2008.

[35] Dong-Xia Wang, Xiu-Lan Wen, Feng-Lin Wang,"A Differential Evolutionary Algorithm for Flatness Error Evaluation",AASRI Procedia, vol.1,pp238-243,2012

[36] M.R.Tanweer, S.Suresh, and N.Sundararajan, " Self regulating particle swarm optimization algorithm", Information Sciences, vol. 294, pp. 182-202, 2015. 
Figures

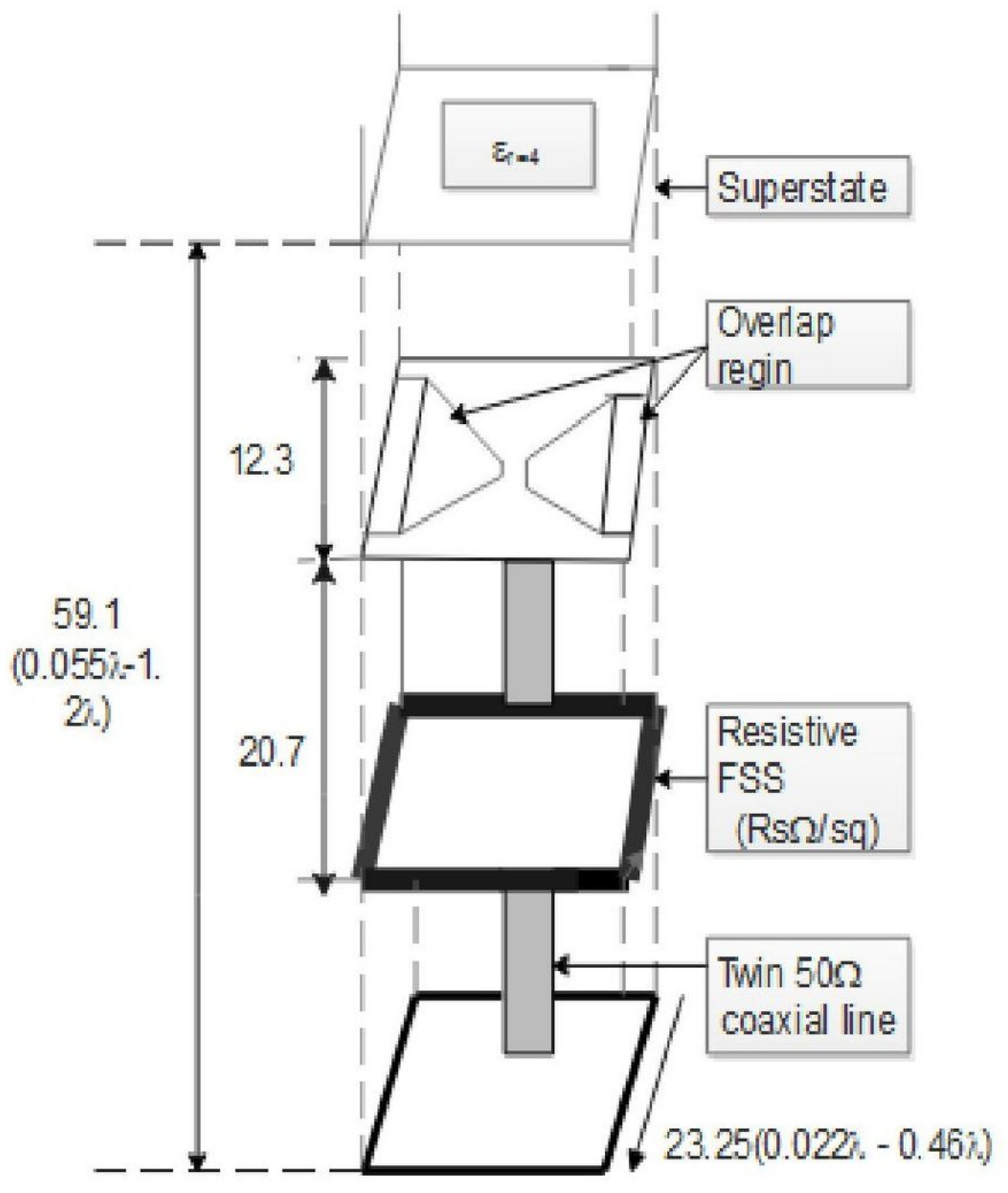

Figure 1

Individual cell of resistive FSS with tightly coupled Bowtie array 


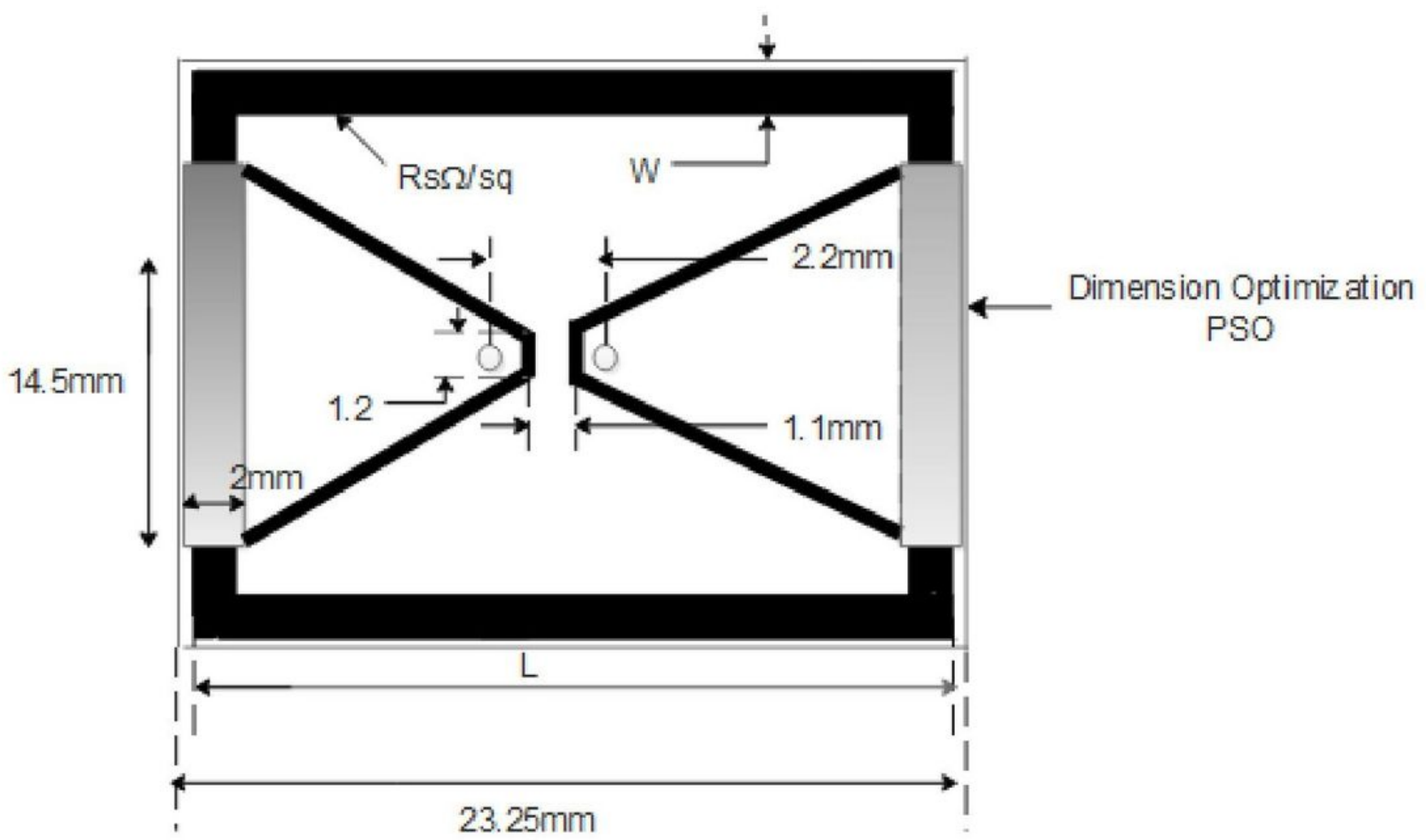

Figure 2

Top view of unit cell 


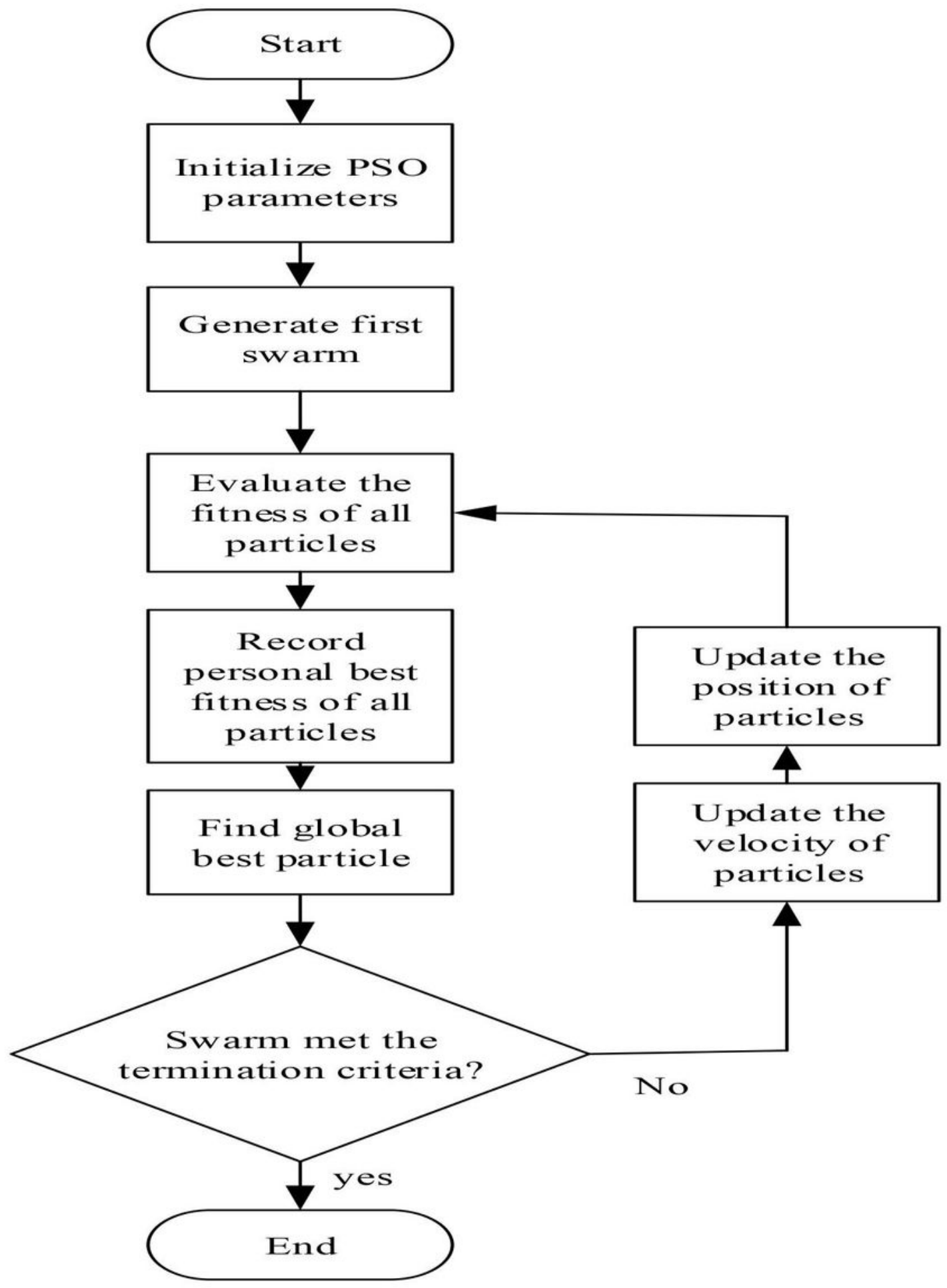

Figure 3

Flowchart of proposed PSO algorithm 


\begin{tabular}{|lllllllll}
\hline la & $W_{a p}$ & $w_{s}$ & $d$ & $s$ & l & w \\
\hline
\end{tabular}

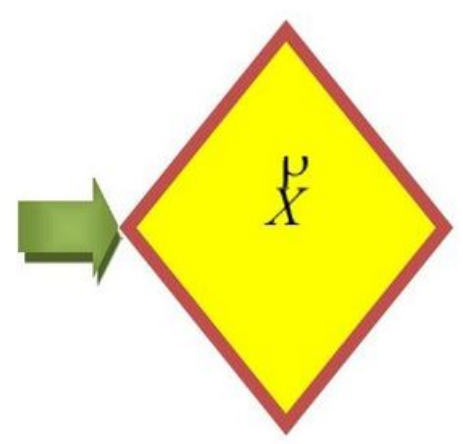

Figure 4

Solution Encoding

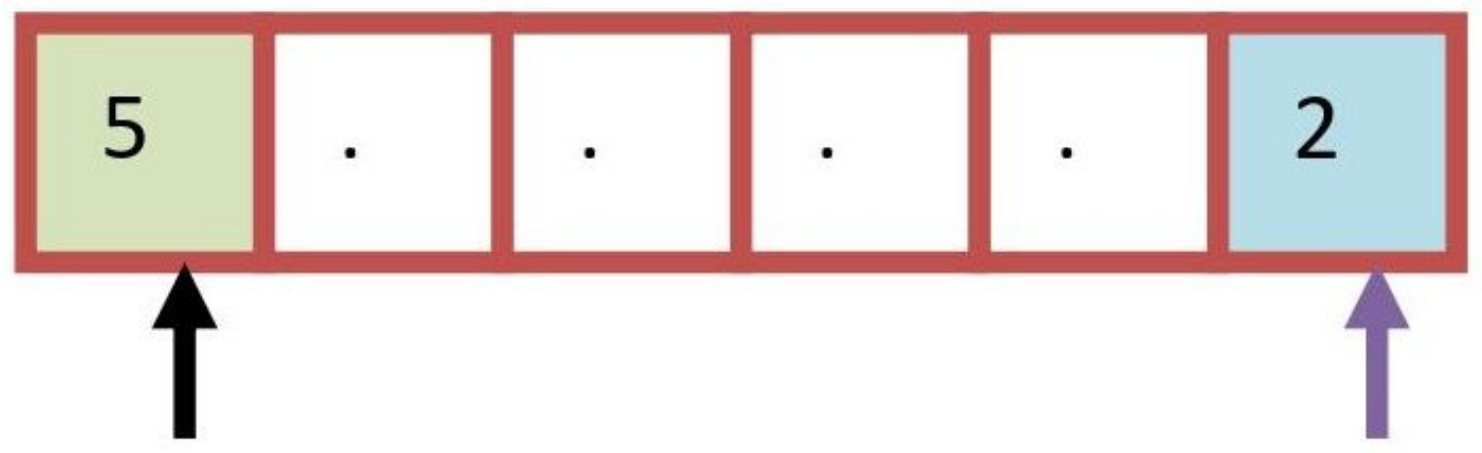

Highest

fitness
Lowest

fitness

Figure 5

Illustration of fitness based position update 


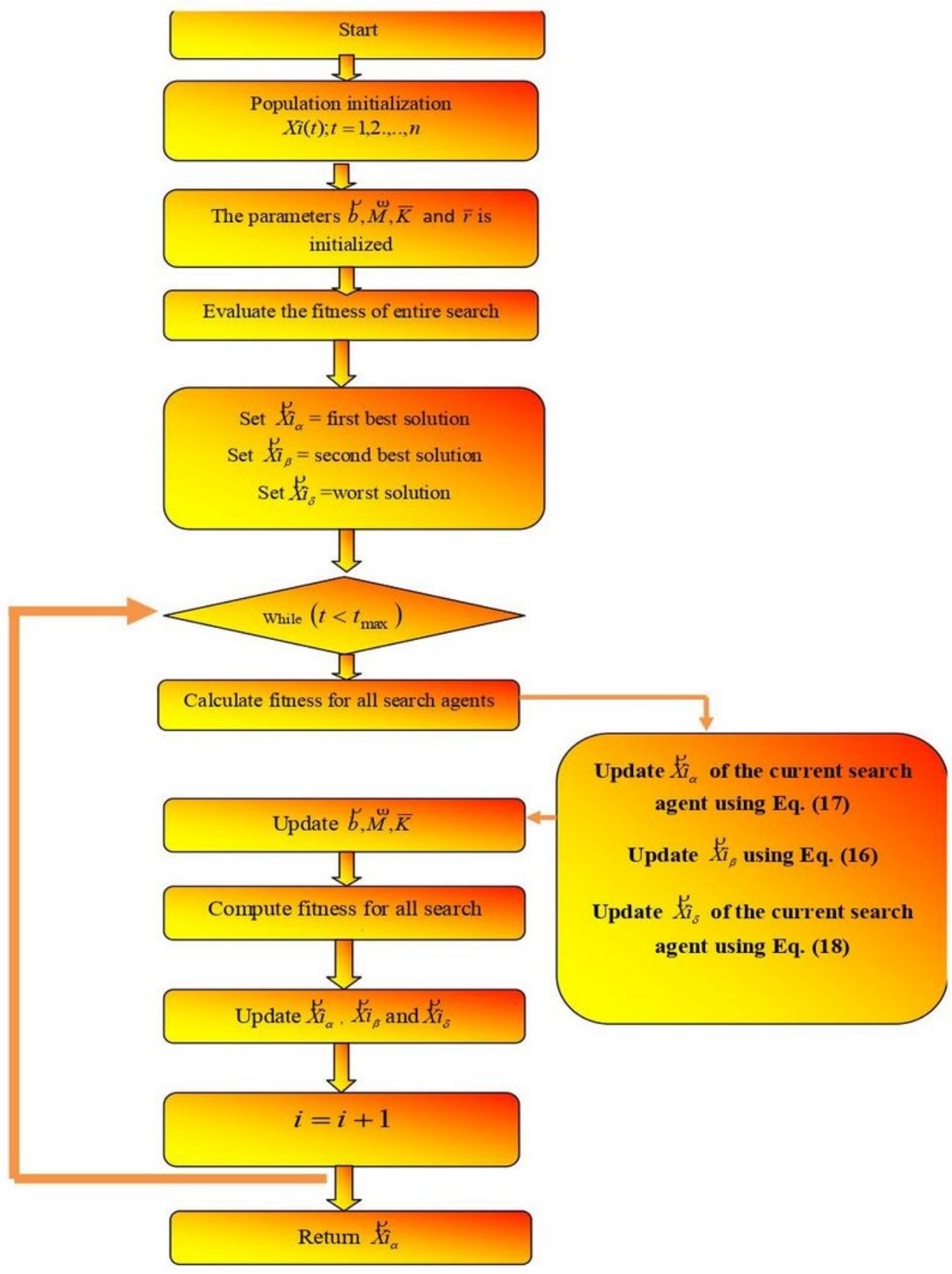

Figure 6

Flow chart of the proposed IGWO-FU model 


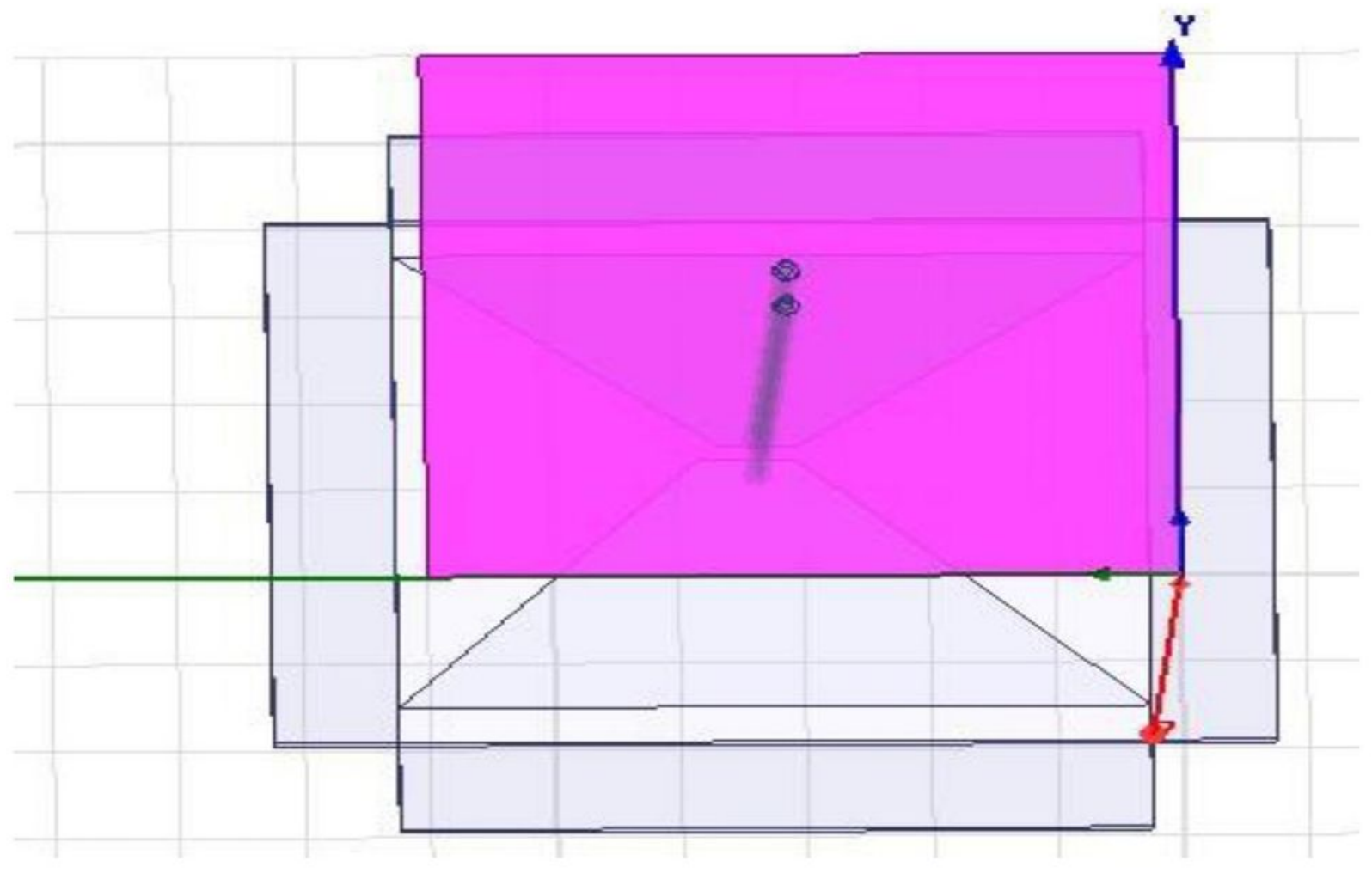

Figure 7

Proposed HFSS model for bowtie antenna 


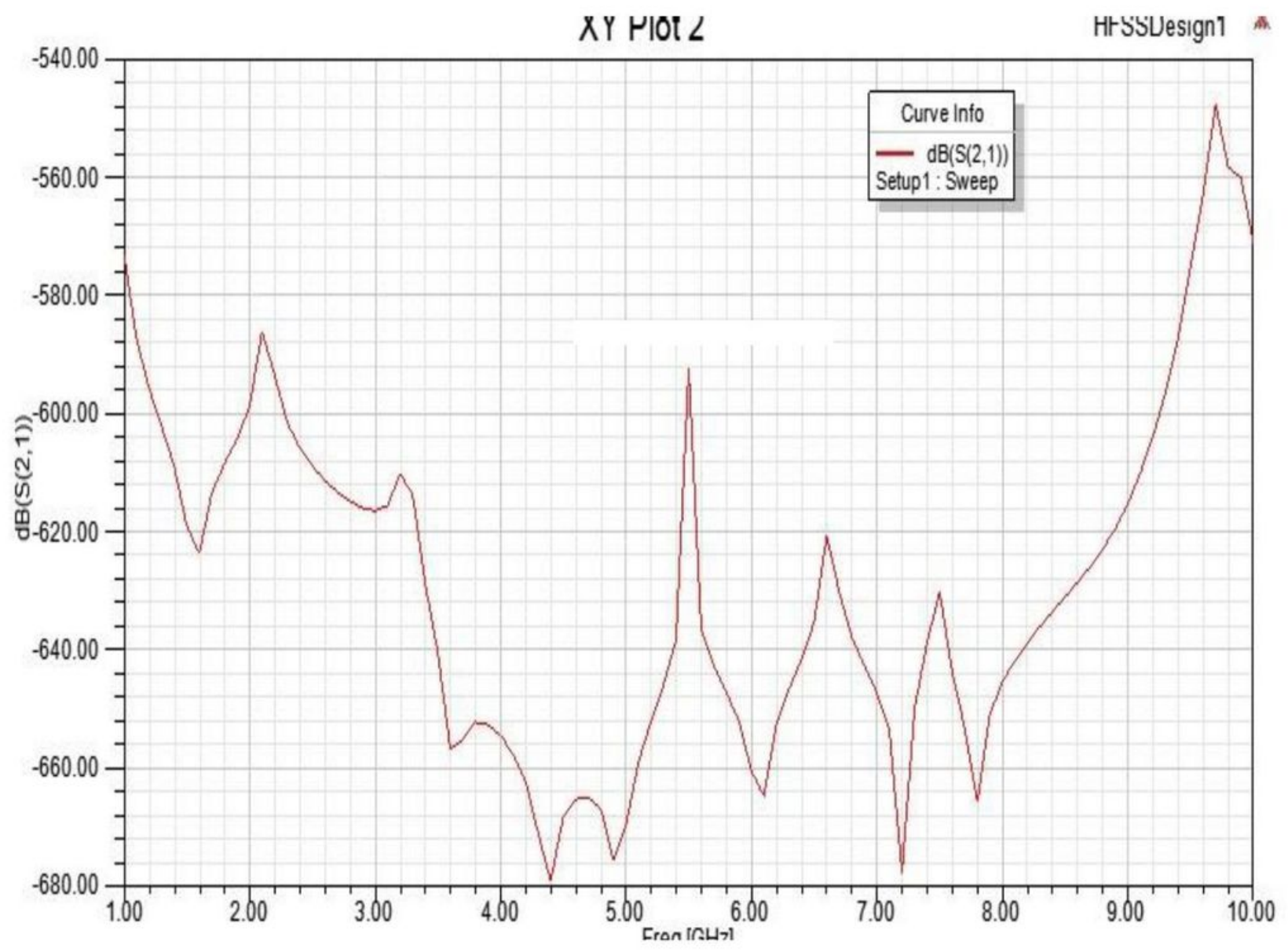

Figure 8

Output graph of the proposed model 


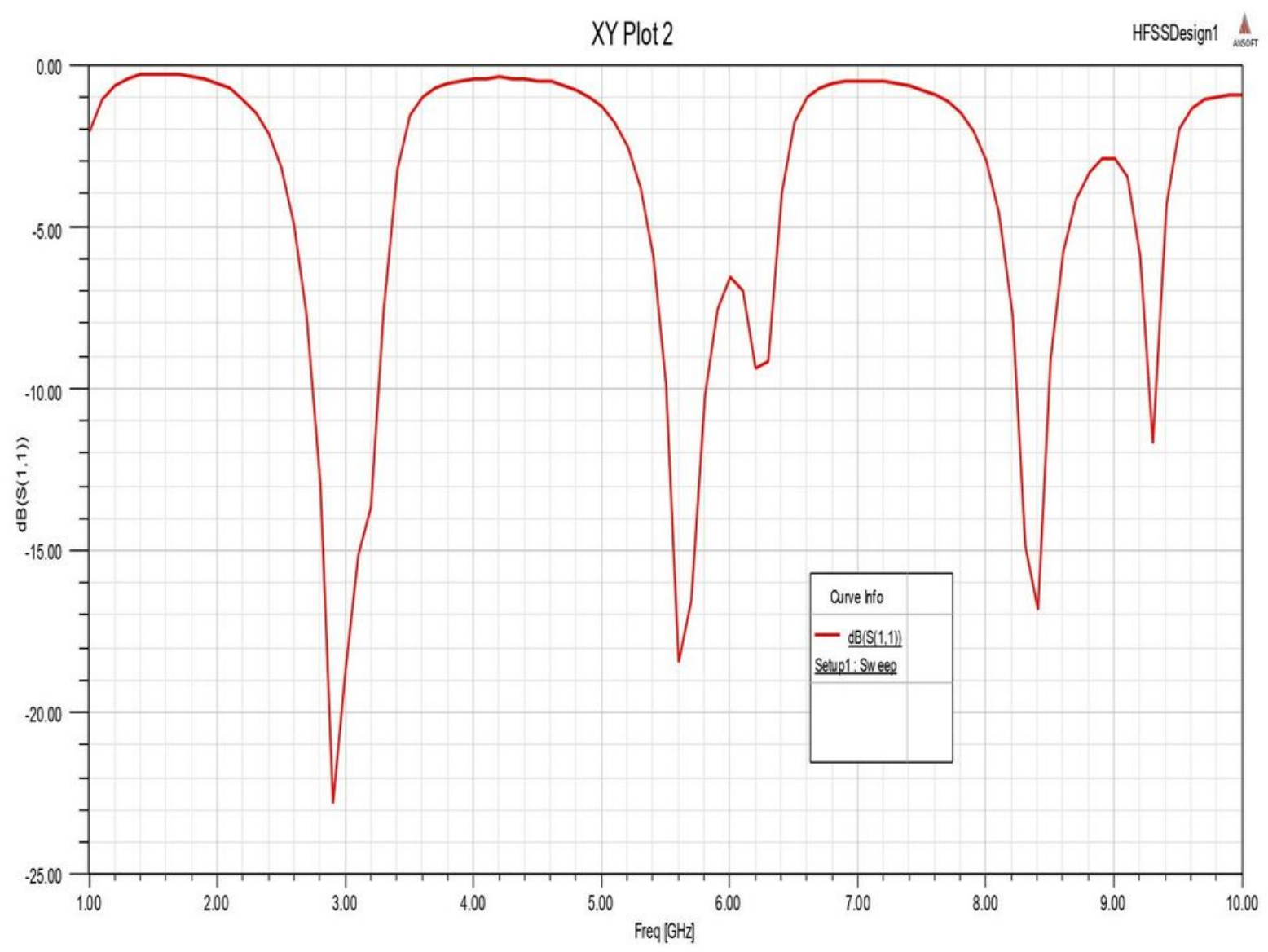

Figure 9

Output graph for Rectangular plot 

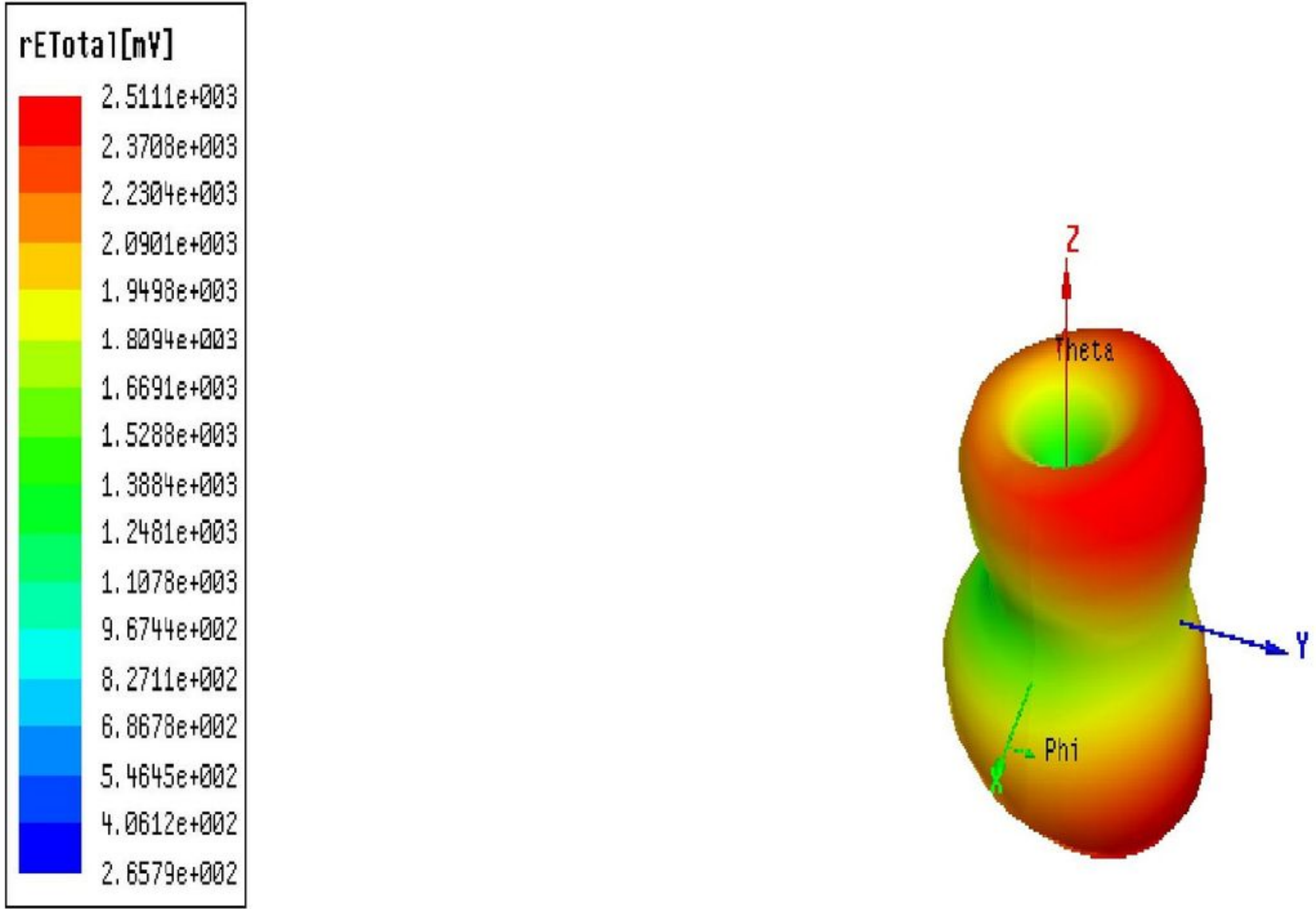

Figure 10

Output graph for polar plot of Radiation Emission 


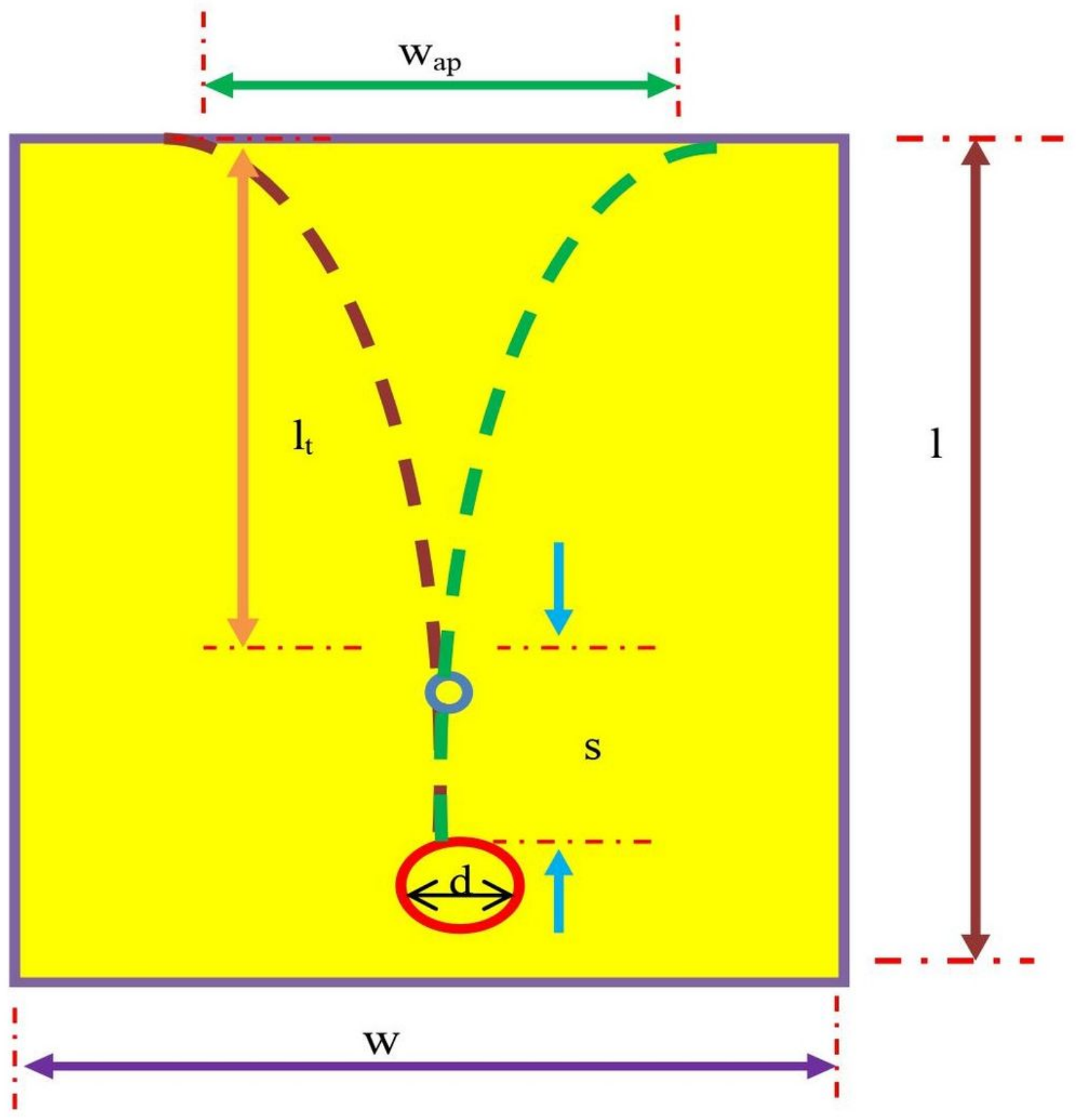

Figure 11

Illustration of geometry of Simple vivaldi antenna 


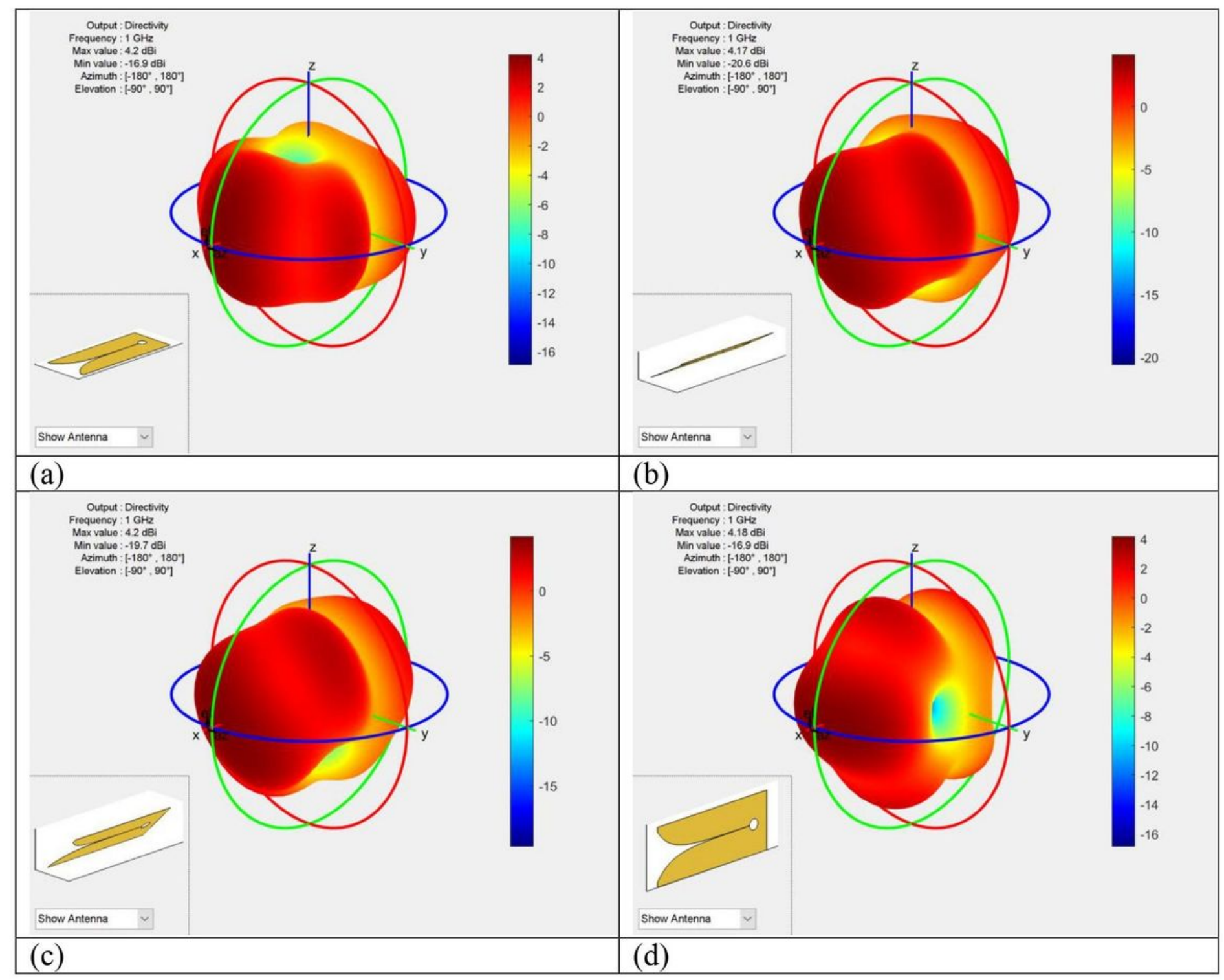

Figure 12

3D pattern of Vivaldi antenna at the rotating angle of (a) $0^{\circ}$ (b) $30^{\circ}{ }^{\circ}$ (c) $45^{\circ}$ (d) $90^{\circ}$ 


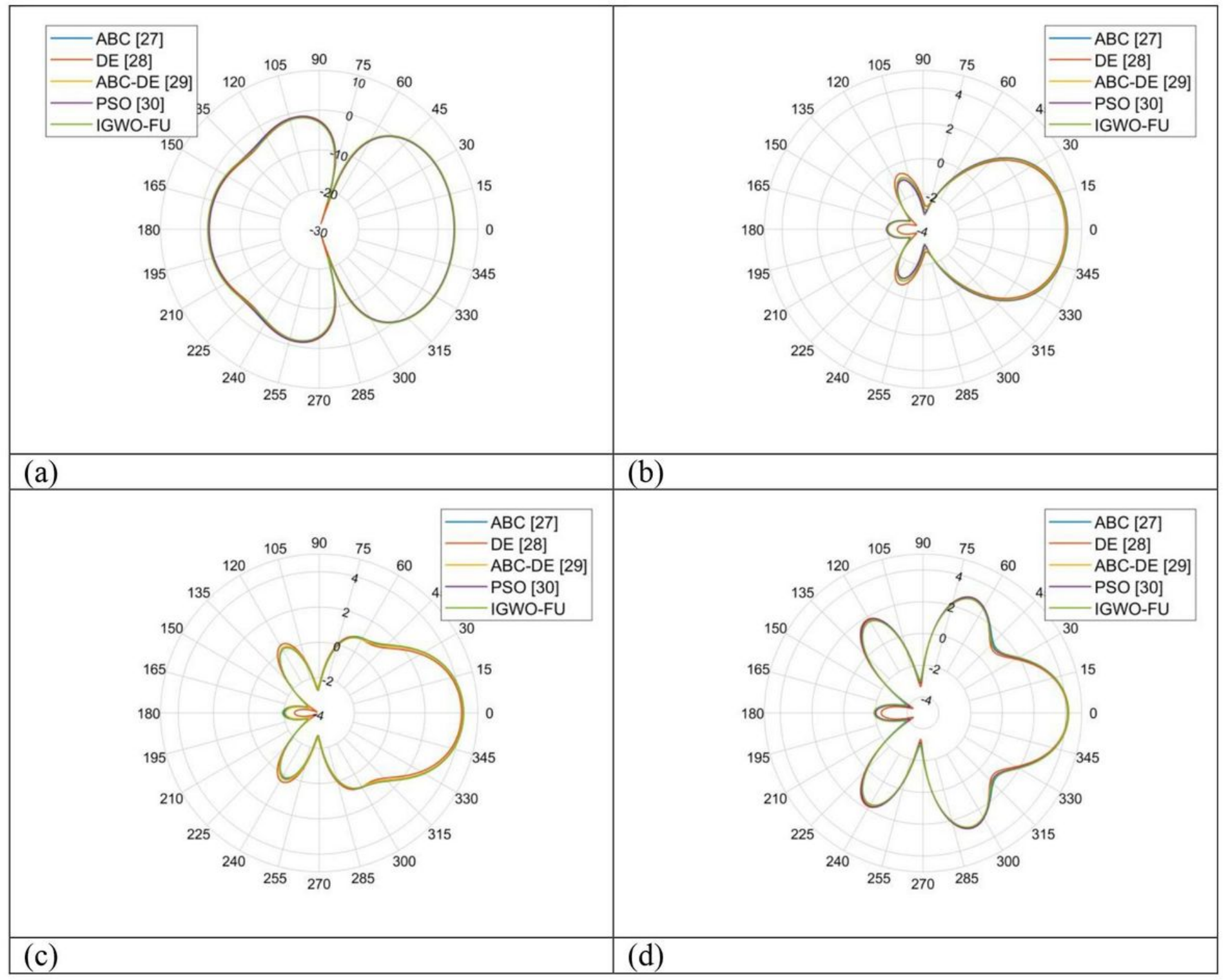

\section{Figure 13}

Polar plot exhibiting the directivity of optimized antenna for traditional and proposed IGWO-FU at (a) tilt angle $=0^{\circ}$ (b) tilt angle $=30^{\circ}$, (c) tilt angle $=45^{\circ}$ and (d) tilt angle $=90^{\circ}$. 